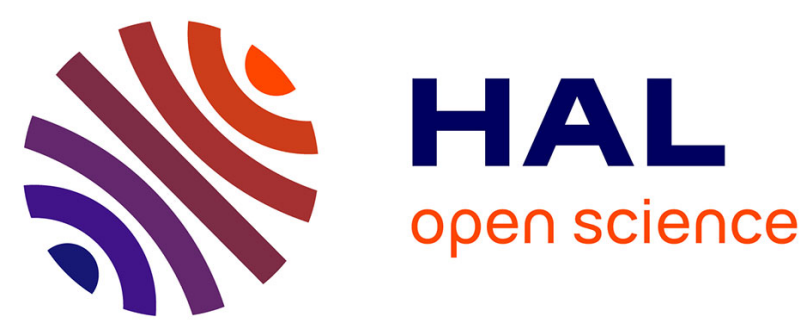

\title{
Chondrules in CK carbonaceous chondrites and thermal history of the CV-CK parent body
}

\author{
Noël Chaumard, Bertrand Devouard
}

\section{To cite this version:}

Noël Chaumard, Bertrand Devouard. Chondrules in CK carbonaceous chondrites and thermal history of the CV-CK parent body. Meteoritics and Planetary Science, 2016, 10.1111/maps.12599 . hal01266275

\section{HAL Id: hal-01266275 \\ https://hal.sorbonne-universite.fr/hal-01266275}

Submitted on 2 Feb 2016

HAL is a multi-disciplinary open access archive for the deposit and dissemination of scientific research documents, whether they are published or not. The documents may come from teaching and research institutions in France or abroad, or from public or private research centers.
L'archive ouverte pluridisciplinaire HAL, est destinée au dépôt et à la diffusion de documents scientifiques de niveau recherche, publiés ou non, émanant des établissements d'enseignement et de recherche français ou étrangers, des laboratoires publics ou privés. 
Chondrules in CK carbonaceous chondrites and thermal history of the CV-CK parent body

\author{
Noël CHAUMARD ${ }^{\mathrm{a}, \mathrm{b}, \boldsymbol{}}$, Bertrand DEVOUARD ${ }^{\mathrm{a}, \mathrm{c}}$ \\ ${ }^{a}$ Laboratoire Magmas et Volcans, CNRS UMR 6524, Université Blaise Pascal, OPGC-IRD, 5 rue Kessler, 63038 Clermont- \\ Ferrand Cedex, France \\ ${ }^{\mathrm{b}}$ Institut de Minéralogie, de Physique des Matériaux, et de Cosmochimie (IMPMC), Sorbonne Universités, Muséum national \\ d'histoire naturelle, UPMC Univ. Paris 06, UMR CNRS 7590, IRD UMR 206, 57 rue Cuvier, CP52, F-75231 Paris Cedex 5 ,
} France

${ }^{c}$ Aix-Marseille Université, CNRS, IRD, CEREGE UM34, BP 80, 13545 Aix en Provence, France

"Corresponding author. E-mail: nchaumard@mnhn.fr 


\section{ABSTRACT}

CK chondrites are the only group of carbonaceous chondrites with petrologic types ranging from 3 to 6 . It is commonly reported than $\sim 15$ vol\% of CK4-6 samples are composed of chondrules. The modal abundance of chondrules estimated here for 18 CK3-6 (including 5 $\mathrm{CK} 3 \mathrm{~s}$ ) ranges from zero (totally recrystallized) to $50.5 \%$. Although almost all chemically reequilibrated with the host matrix, we recognized in CK3s and Tanezrouft (Tnz) 057 (CK4) up to $85 \%$ of chondrules as former Type I chondrules. Mean diameters of chondrules range from 0.22 to $1.05 \mathrm{~mm}$ for Karoonda (CK4) and Tnz 057 (CK4), respectively. Up to $60 \%$ of chondrules in CK3-4 are surrounded by igneous rims (from $\sim 20 \mu \mathrm{m}$ to $2 \mathrm{~mm}$ width). Zoned olivines were found in unequilibrated chondrules from DaG 431 (CK3-an), NWA 4724 (CK3.8), NWA 4423 (CK3.9), and Tnz 057 (CK4). We modeled Fe/Mg interdiffusion profiles measured in zoned olivines to evaluate the peak metamorphic temperatures and time scales of the CK parent body metamorphism, and proposed a two-stage diffusion process in order to account for the position of inflection points situated within chondrules. Time scales inferred from $\mathrm{Fe} / \mathrm{Mg}$ interdiffusion in olivine from unequilibrated chondrules are on the order of tens to a hundred of thousand years (from 50 to 70000 years for peak metamorphic temperatures of 1140 and $920 \mathrm{~K}$, respectively). These durations are longer than what is commonly accepted for shock metamorphism and shorter than what is required for nuclide decay. Using the concept of a continuous $\mathrm{CV}-\mathrm{CK}$ metamorphic series, which is reinforced by this study, we estimated peak metamorphic temperatures $<850 \mathrm{~K}$ for CV, 850-920 K for CK3, and 920$1140 \mathrm{~K}$ for CK4-6 chondrites considering a duration of 70000 years.

\section{INTRODUCTION}

CK (Karoonda-like) carbonaceous chondrites (CCs) are mainly composed of chondrules, calcium-aluminum-rich inclusions (CAIs), and lithic clasts (i.e., dark inclusions (DIs); Kallemeyn et al., 1991; Chaumard et al., 2009) embedded in variable proportions in a recrystallized and chemically equilibrated matrix dominated by $\mathrm{Fe}$-rich olivine $\left(\sim \mathrm{Fa}_{29}-\mathrm{Fa}_{32}\right.$; Scott and Taylor, 1985; Kallemeyn et al., 1991; Noguchi, 1993). CKs are highly oxidized carbonaceous chondrites, with metal/magnetite ratios close to zero and matrix olivines containing up to $\sim 0.5 \mathrm{wt} \% \mathrm{NiO}$ (Scott and Taylor, 1985; Kallemeyn et al., 1991; Noguchi, 1993; Geiger and Bischoff, 1995; Righter and Neff, 2007). Refractory lithophile abundances in CKs are intermediate between those of the $\mathrm{CV}$ and $\mathrm{CO}$ groups, as are their oxygen isotope compositions which overlap the CV and CO groups (e.g., Kallemeyn et al., 1991; Greenwood et al., 2004, 2010a; Wasson et al., 2013).

It has been reported that CK4-6 contain $\sim 15$ volume $\%$ of chondrules, the remainder being mostly matrix, including matrix formed by recrystallization of chondrules. The average sizes of CK chondrules are close to those described in CVs, 0.7 and $1.0 \mathrm{~mm}$, respectively (e.g., Scott et al., 1996; Weisberg et al., 2006; and references therein). Most chondrules in CKs have porphyritic textures and a mineralogy dominated by olivine. Porphyritic olivine and olivine-pyroxene (PO, POP), granular olivine (GO), barred olivine and olivine-pyroxene (BO, $\mathrm{BOP}$ ), and radial pyroxene (RP) chondrules were described in the CK3s Watson 002, NWA 1559, DaG 431 and in some CK4-6 (Kallemeyn et al., 1991; Keller et al., 1992; Geiger et al., 1993; Brandstätter et al., 2003; Bukovanská et al., 2003; Tomeoka et al., 2005; Pratesi et al., 2006). Igneous rims were only described around a few chondrules in the two CK3 NWA 1559 
and DaG 431 (Zipfel et al., 2000; Rubin, 2010), while they surround 50\% of chondrules in CVs (Rubin, 1984a).

Unlike enstatite, Rumuruti, and ordinary chondrites (OCs), most CCs are primitive (petrologic types from 1 to 3 ), i.e., they have not been affected by extensive thermal processes on their parent body(ies) (e.g., McSween, 1979). However, the CK group forms a unique metamorphic series among CCs (from petrologic types 3 to 6) and suffered intense thermal metamorphism (Kallemeyn et al., 1991). Several methods such as olivine-spinel geothermometry, pyroxene and plagioclase compositions, isotopic data, and distribution of $\mathrm{Ti}$ between ilmenite and magnetite have been used to estimate the peak temperature of the CK parent body metamorphism (Clayton et al., 1977; Geiger and Bischoff, 1991; Noguchi, 1993; Clayton and Mayeda, 1999; Nakamuta et al., 2001; Tachibana et al., 2002; Neff and Righter, 2006; Righter and Neff, 2007; Chaumard et al., 2014). The peak metamorphic temperatures thus proposed for $\mathrm{CK}$ chondrites range from 550 to $1270 \mathrm{~K}$.

Based on these estimations of the peak metamorphic temperatures, as well as isotopic, chemical, and petrological analyses, it has been proposed that CVs and CKs form a continuous metamorphic series deriving from a single parent body (Greenwood et al., 2003, 2004, 2010a; Devouard et al., 2006; Chaumard et al., 2009, 2014; Wasson et al., 2013; Davidson et al., 2014). Different CV-CK parent body models were suggested such as a thermally stratified parent body (Greenwood et al., 2010a, b) and a differentiated asteroid (e.g., Weiss et al., 2010; Elkins-Tanton et al., 2011; Humayun and Weiss, 2011). An alternative model proposed by Chaumard et al. $(2009,2012)$ suggests an initial CV-type parent body disrupted by shock then metamorphosed by radiative heating during close approaches to the Sun. More recently, Wasson et al. (2013) also suggested that CKs formed from CVs, which were shocked, buried, affected by aqueous alteration and then annealed. However, though the effects of CK parent body metamorphism have been previously reported, the peak metamorphic temperature and time scale of this thermal event are still poorly constrained.

The aim of this work is to study chondrules in a suite of CK chondrites to characterize their modifications during metamorphism and to investigate the plausible CV-CK relationship. After a general physical study of the abundance and size of chondrules, we focused our study on the description of the texture and petrology of the unequilibrated chondrules present in CK3-4. Indeed, the recent discoveries of CKs, in particular of CK3s, by systematic Antarctic and Saharan collecting expeditions makes possible a detailed study of the first steps of the metamorphism of chondrules. Though most CKs are texturally, chemically, and mineralogically equilibrated, CK3 and some CK4 chondrites display several indicators of disequilibrium such as chemical zoning in olivine from Mg-rich (Type I) chondrules. In these unequilibrated chondrules, olivines have not been totally re-equilibrated with the host matrix during thermal metamorphism that caused $\mathrm{Fe} / \mathrm{Mg}$ interdiffusion between silicates in matrix (Fe-rich) and those present in these chondrules. We used a numerical modeling of the $\mathrm{Fe} / \mathrm{Mg}$ interdiffusion to quantify the peak metamorphic temperature(s) and time scale(s) of the CK thermal event. This method, though used for the Allende CV3 chondrite (e.g., Weinbruch et al., 1994; Cuvillier et al., 2015) and anomalous CK3 Watson 002 (Davidson et al., 2014), has never been extended to higher CK petrologic types en masse. Results obtained from this quantitative understanding of the cation diffusion in zoned olivine will thus provide new constraints on the parent body models proposed for $\mathrm{CV}-\mathrm{CK}$. 


\section{SAMPLES AND METHODS}

\subsection{Samples}

Textural and petrological observations were carried out on $18 \mathrm{CK}$ chondrites. We also studied $5 \mathrm{CV}$ chondrites for comparison. Samples used have been provided mostly by the Muséum national d'Histoire naturelle (Paris, France) and the NASA Meteorite Working Group (Houston, USA). All samples studied here are listed in the Table 1. Slices of Tnz 057 were also loaned by Frederic Béroud and Christophe Boucher.

\subsection{Modal abundance measurements}

We measured modal abundances of chondrules for all CV and CK samples listed in Table 1. We used the method described by Chaumard et al. (2014) for the measurement of the modal abundance of CAIs. When it was possible, Type I chondrules were recognized on the basis of their texture and mineralogy, as well as $\mathrm{Mg}$ concentrations in chemical mapping. Modal abundances reported here include igneous rims and chondrule fragments. Even if most chondrules observed have rounded shapes, we calculated an "equivalent diameter" corresponding to the diameter of the surface area of a chondrule assimilated into a circular object.

\subsection{Analytical methods}

Backscattered electron (BSE) imaging and energy dispersive X-ray spectrometry (EDS) mapping were performed using a JEOL JSM-5910 LV scanning electron microscope (SEM) equipped with a PGT Si(Li) detector at Laboratoire Magmas et Volcans (LMV) in Clermont-Ferrand. EDS elemental maps were obtained using an accelerating voltage of 15 $\mathrm{kV}$. RGB compositional maps have a resolution of $\sim 2 \mu \mathrm{m} / \mathrm{pixel}$.

Chemical profiles were measured across zoned olivines, with $3 \mu \mathrm{m}$ spacing using a CAMECA SX-100 electron microprobe at LMV. We used an accelerating voltage of $15 \mathrm{kV}$ and a beam current of $30 \mathrm{nA}$. Beam diameter was constant at $\sim 1 \mu \mathrm{m}$. Standards used for silicates were wollastonite $(\mathrm{Si}, \mathrm{Ca})$, fayalite $(\mathrm{Fe})$, forsterite $(\mathrm{Mg})$, synthetic $\mathrm{Al}_{2} \mathrm{O}_{3}(\mathrm{Al})$, pyrophanite $(\mathrm{Mn})$, synthetic $\mathrm{Cr}_{2} \mathrm{O}_{3}(\mathrm{Cr})$, and synthetic $\mathrm{NiO}$ or San Carlos olivine (Ni). We used a TAP crystal for the analyses of $\mathrm{Mg}, \mathrm{Al}$, and $\mathrm{Si}$, a PET crystal for $\mathrm{Ca}, \mathrm{Cr}$, and a LIF crystal for $\mathrm{Mn}, \mathrm{Fe}$, and $\mathrm{Ni}$. We used the CAMECA $\varphi_{\mathrm{p}(\mathrm{z})}$ program for matrix corrections.

Crystallographic orientations of olivines were determined using electron backscattered diffraction (EBSD). We used a Bruker's QUANTAX CrystAlign EBSD analysis system on a JEOL JSM-5910 LV SEM at LMV. EBSD patterns of olivine were fit using Pnma as the space group (the standard setting in the International Tables of X-ray Crystallography for denoting the space group of olivine), for a composition of $\mathrm{Mg}_{1.84} \mathrm{Fe}_{0.16} \mathrm{SiO}_{4}$, and with $\mathrm{a}=$ $4.758, \mathrm{~b}=10.21, \mathrm{c}=5.989$ (Merli et al., 2001). Since historically and most commonly used in the literature, we will adopt throughout this manuscript the directions [001], [100], and [010] for diffusion in olivine considering the Pbnm space group. We used the Esprit software to produce phase maps, as well as orientation and misorientation maps. EBSD maps were acquired using an accelerating voltage of $15 \mathrm{kV}$, for surfaces areas ranging from 0.13 to 4 $\mathrm{mm}^{2}$ at resolutions ranging from 0.7 to $3.8 \mu \mathrm{m} /$ pixel. 


\section{RESULTS}

\subsection{Modal abundances and sizes of chondrules}

Modal abundances and sizes of chondrules measured for the CV and CK chondrites investigated here are presented in Table 2 . From $\sim 20$ to $60 \%$ of chondrules in CKs are surrounded by igneous rims. All modal abundances of chondrules are given as a percentage of the total area studied (area\%). When several sections of a single sample were analyzed, we reported standard deviations corresponding to 1 sigma.

\section{In CV chondrites}

Modal abundances measured for Allende $\left(37.6 \% ; 9.2 \mathrm{~cm}^{2}\right)$, Kaba $\left(55.7 \% ; 0.75 \mathrm{~cm}^{2}\right)$, and Bali $\left(44.7 \%, 1.83 \mathrm{~cm}^{2}\right)$ are slightly different than those reported by McSween (1977), which are $45.9 \%, 35.9 \%$, and $33.0 \%$ (including lithic and mineral fragments), respectively. Ebel et al. $(2008,2009)$ reported for Allende $24.9 \%$ to $32.6 \%$ of chondrules (including isolated olivine grains and lithic fragments). All these values vary around the typical value accepted for CV chondrites (45\%; Scott et al., 1996). NWA 779 contains $39.1 \pm 1.2 \%$ (12.15 $\left.\mathrm{cm}^{2}\right)$ of chondrules, while NWA 2900 contains only $18.5 \% \pm 3.8 \%\left(25.56 \mathrm{~cm}^{2}\right)$ of chondrules.

Chondrules recognized during the modal abundance measurements of the $5 \mathrm{CVs}$ investigated have diameters ranging from 0.04 to $4.28 \mathrm{~mm}$ (Table 2). The mean values of chondrule diameters range from 0.31 to $0.96 \pm 0.07$ in Kaba and NWA 2900, respectively. These values are similar to those reported in the literature, i.e., approximately $1.0 \mathrm{~mm}$ (e.g., Scott et al., 1996; Rubin, 2010).

\section{In CK chondrites}

Modal abundances measured for CK chondrites range from zero to $50.5 \%$ in LEW $87009\left(\mathrm{CK} 6 ; 0.77 \mathrm{~cm}^{2}\right)$ and Maralinga $\left(\mathrm{CK} 4 ; 4.05 \mathrm{~cm}^{2}\right)$, respectively. Values reported here for Maralinga and NWA $5733\left(45.0 \% ; 1.31 \mathrm{~cm}^{2}\right)$ are close to the value of $45 \%$ commonly accepted for CVs (Table 2). Excluding Maralinga and NWA 5733, the mean value of the modal abundance of chondrules calculated for all other CK chondrites is $19.3 \pm 7.0 \%$. This mean value increases to $22.5 \pm 11.1 \%$ if we consider Maralinga and NWA 5733. Except for PCA 82500 (CK4/5) (10.7\%; $\left.0.42 \mathrm{~cm}^{2}\right)$ and LEW 87009 (CK6), values determined in this study are higher than the value commonly accepted for CK4-6 (15\%; Scott et al., 1996) (Table 2). We found no significant differences of modal abundances of chondrules between CK3s $(22.1 \pm 3.1 \%)$ and CK4s $(29.5 \pm 11.1 \%$ and $23.4 \pm 3.8 \%$ with and without Maralinga and NWA 5733, respectively). However, we observed a slight diminution from CK4s to CK6s.

On the basis of their size, texture, and mineralogy, we estimated the abundance of Type I chondrules in the CK3s and Tnz 057 (Table 2). Although most of them are actually chemically re-equilibrated with the host matrix due to parent body metamorphism, between 40 and $85 \%$ of chondrules observed in these sections were recognized as former Type I chondrules. They include all microporphyric chondrules with euhedral olivine, chondrules with barred olivine cores and granular rims, and opaque-rich chondrules (Fig. 1).

CK chondrites investigated contain chondrules with diameters ranging from 0.08 to $5.90 \mathrm{~mm}$ (Table 2). Mean chondrule diameters range from 0.47 to $1.05 \pm 0.05 \mathrm{~mm}$ for Maralinga and Tnz 057, respectively. The mean value of $0.22 \mathrm{~mm}$ calculated for Karoonda is not considered here because the section investigated contains numerous chondrule fragments. We observed no distinct variation of the mean diameters between the different petrologic types of CK chondrites. 


\subsection{Textures, mineralogy and chemical compositions of unequilibrated chondrules}

As described in the literature, the mineralogy of chondrules in CK chondrites is dominated by olivine. An interstitial fine-grained mixture composed of pyroxene and plagioclase was also observed in several chondrules (Fig. 1). Although CKs are commonly described as equilibrated chondrites, they contain chondrules in which the chemical composition of olivine is not completely re-equilibrated with the host matrix (Fig. 1a-d). These unequilibrated chondrules have cores composed of Mg-rich olivine while their exteriors contain olivine grains partially equilibrated with the Fe-rich matrix. These unequilibrated chondrules were observed in all CK3s investigated and in Tnz 057.

We recognized two different textures of unequilibrated chondrules (Fig. 1-3). Most of them are composed of large, mostly anhedral, olivine grains (up to few hundred microns in size) (Fig. 2a-d). Sometimes composed of a single olivine crystal, these chondrules may be related to isolated forsterite grains. Diffusion fronts observed in this type of chondrule are most likely constrained by intracrystalline diffusion, as well as diffusion at grain boundaries and along fractures (Fig. 3b, 4). Sometimes, these chondrules display at their borders olivine grains containing numerous micron-sized vesicles, pits, and tiny inclusions of opaque phases (mostly magnetite and sulfides) (Fig. 1c, 5). These vesiculated grains of olivine are chemically equilibrated with matrix olivines. These vesiculated olivines display different crystallographic orientations compared to zoned olivines situated in the core of unequilibrated chondrules (Fig. 5).

Few unequilibrated chondrules are entirely composed of euhedral olivine grains (Fig. $1 \mathrm{~b}, 2 \mathrm{e}-\mathrm{h}, 3 \mathrm{a})$. These chondrules, although formed by olivine grains with random crystallographic orientations (Fig. 2g), display diffusion fronts parallel to the matrixchondrule interfaces. In this case, the evolution of these diffusion fronts appears to be mostly constrained by the cation diffusion velocity (at least for $\mathrm{Mg}$ and $\mathrm{Fe}$ ) within the fine-grained pyroxene-plagioclase mixture situated between euhedral olivine crystals.

Up to $\sim 60 \%$ of chondrules observed in CK3-4s, including unequilibrated chondrules, are surrounded by igneous rims with porphyritic or granular textures. With thicknesses ranging from $\sim 20 \mu \mathrm{m}$ to $\sim 2 \mathrm{~mm}$ (Fig. 1), these rims are mainly composed of Ca-rich pyroxene, Cr-rich magnetite, olivine, and plagioclase in various proportions. These minerals have size ranging from $\sim 10$ to $\sim 250 \mu \mathrm{m}$. Ca-rich pyroxene is either granular or present as laths (up to $\sim 30 \mu \mathrm{m}$ long) displaying a characteristic texture of dehydrated phyllosilicates. Magnetite occurred either as grains homogeneously distributed within the igneous rim (up to $\sim 50 \mu \mathrm{m}$ in size; Fig. 1f) or as large rounded lumps (up to $\sim 250 \mu \mathrm{m}$; Fig. 1d). Olivine grains are chemically equilibrated with the host matrix.

\subsection{Quantitative study of $\mathrm{Fe} / \mathrm{Mg}$ interdiffusion in olivine}

\section{Diffusion profiles in olivine}

We measured by electron probe micro-analysis (EPMA) 24 chemical profiles in unequilibrated chondrules either composed of barred, anhedral, and euhedral zoned olivines. We acquired 6 chemical profiles in DaG 431, 4 in NWA 4724, 10 in NWA 4423, and 4 in Tnz 057. All chemical profiles measured display $\mathrm{Fe}, \mathrm{Ni}$, and $\mathrm{Mn}$ diffusion from matrix to chondrules. Unlike these elements, $\mathrm{Mg}, \mathrm{Al}, \mathrm{Ca}$, and $\mathrm{Cr}$ are enriched in olivine from chondrules and diffuse towards the matrix. These chemical zonations are illustrated in Fig. 6. The chemical compositions of the cores and borders of zoned olivines in which the zoning profiles were measured are reported in Table 3. 


\section{Chondrule and olivine selection for quantitative study}

The acquisition of a chemical profile in a chondrule composed of euhedral olivines implies an analysis through different crystals (Fig. 1b, 2e-h, 3a). To simplify the modeling of the diffusion profiles, we thus decided to model only those passing through a single olivine crystal (Fig. 4). For this reason, we only used chemical profiles taken within chondrules composed of anhedral olivines and measured perpendicular to the matrix/chondrule interfaces where both igneous rims and vesiculated olivines are lacking.

\section{Profile fitting}

As shown in Fig. 1a-d, 3-4, diffusion fronts are situated within chondrules. In consequence, inflexion points of chemical profiles do not correspond to the initial chondrule/matrix interfaces. In addition, we can note here that the inflexion points are never situated within vesiculated olivines or at the non vesiculated/vesiculated olivine interfaces (Fig. 1c, 5).

The chemical profiles measured here can be modeled by a simple model of diffusion in a semi-infinite medium. To a first approximation, the diffusion of an element $X$ is characterized by the characteristic length-scale of diffusion $(a)$, which can be expressed as:

$$
a=2 \sqrt{D_{X} t}
$$

where $D_{X}$ is the diffusion coefficient of the element $X\left[\mathrm{~m}^{2} . \mathrm{s}^{-1}\right]$ and $t$ the time [s]. Because the diffusion coefficient depends on temperature, an empirical estimate of the diffusion lengths would supply time-temperature curves. This approach was used by Weinbruch et al. (1994) and Cuvillier et al. (2015) to investigate the thermal history of the Allende (CV3) parent body and Davidson et al. (2014) for Watson 002 (anomalous CK3).

However, the unusual configuration of these chemical profiles is problematic. To explain the position of the inflexion points, we could suggest that the formation of the diffusion fronts post-dates the formation of Fe-rich olivine rims around primary $\mathrm{Mg}$-rich olivines, i.e., during fluid-assisted thermal metamorphism (e.g., Brearley and Krot, 2012). In this case, Fe diffused from these secondary Fe-rich rims to the primary $\mathrm{Mg}$-cores. However, this hypothesis appears unlikely regarding the textural and petrological observations reported above. Most of the Fe-rich olivines observed in unequilibrated chondrules do not display the microstructural textures of such secondary Fe-rich olivines that contain both voids and planar dislocations. Only the vesiculated Fe-rich olivine grains situated at the border of some unequilibrated chondrules (Fig. 5) could have been formed during such fluid-assisted thermal metamorphism.

In order to model these unusual chemical profiles, we propose a two-stage alternative model (Fig. 7). In other words, the modeling of the diffusion profiles measured during this work was split into two stages. Solutions of each stage used are described below, for diffusion in 1 dimension and in Cartesian coordinates (Crank, 1975; Philibert, 1985).

Due to the large amount of $\mathrm{Fe}$ available in matrix olivines relative to $\mathrm{Mg}$ from chondrule olivines, the Fe content in matrix would remain constant during the early stages of the chemical re-equilibration. We modeled this first stage of the diffusion process considering an element $\mathrm{X}$ that diffuses from a half-space (matrix in the case of $\mathrm{Fe}$ ) with a concentration $C_{\mathrm{S}}$ maintained at a constant concentration, to another half-space (chondrule in the case of $\mathrm{Fe}$ ) with a concentration $C_{0}$. Thus, the solution of the diffusion equation has the form:

$$
\frac{C(x, t)-C_{\mathrm{S}}}{C_{0}-C_{\mathrm{S}}}=\operatorname{erf}\left(\frac{x}{2 \sqrt{D t}}\right)
$$


where $x$ is the distance $[\mathrm{m}], C(x, t)$ the concentration of the element $\mathrm{X}$ at a given $x$ and $t$, with the initial conditions:

$$
C(x, t)=C_{0}, \quad x>0, \quad t=0
$$

and the boundary conditions:

$$
C(x, t)=C_{\mathrm{S}}, \quad x=0, \quad \forall t>0
$$

Knowing $C_{0}$ and $x$, we determined for each profile the best $C_{\mathrm{S}}-a_{1}$ pair that minimizes the deviation between the chemical profile measured and the solution of the Eq. (2). The $C_{\mathrm{S}}-a_{1}$ pair is considered as best fitting when at least $75 \%$ of our data situated below the inflexion point of the chemical profile measured are fit (Fig. 7). As expressed in Eq. (1), we can thus produce the time-temperature curves of this first stage using the value estimated for $a_{1}$. This duration, at a given temperature, is noticed $t_{1}$ below. The concentration $C_{\mathrm{S}}$ thus obtained for the matrix/chondrule interface corresponds to the presumed content of the element $\mathrm{X}$ in olivine from matrix before the beginning of the diffusion. Although not numerically fit, the chemical profiles measured by Weinbruch et al. (1994) are similar to the theoretical fits obtained using the Eq. (2).

Then, olivine in matrix is progressively depleted in Fe by diffusion into chondrules. The Fe content reaches in fine the value measured in both equilibrated olivines in matrix and at the border of chondrules. During this second stage of the diffusion process, we considered an element $\mathrm{X}$ that diffuses from a half-space (matrix in the case of $\mathrm{Fe}$ ) of a $C_{1}$ concentration (fixed to the value measured by EPMA at the matrix/chondrule interface), to another halfspace (chondrule in the case of $\mathrm{Fe}$ ) of a concentration $C\left(x, t_{1}\right)$. In this case, the solution has the form:

$$
\frac{C(x, t)-C\left(x, t_{1}\right)}{C_{1}-C\left(x, t_{1}\right)}=\frac{1}{2} \cdot \operatorname{erf} C\left(\frac{x}{2 \sqrt{D t}}\right)
$$

with the initial conditions:

$$
t=0\left\{\begin{array}{cc}
x<0 & C(x, t)=C_{1} \\
x>0 & C(x, t)=C\left(x, t_{1}\right)
\end{array}\right.
$$

Then, we are able to determine the diffusion length of this second stage $\left(a_{2}\right)$ (Fig. 7). The total duration of this two-stage diffusion process is obtained by the addition of the two durations inferred from the diffusion lengths estimated for each stage $\left(a_{1}\right.$ and $\left.a_{2}\right)$.

\section{Diffusion coefficients in olivine}

The literature contains numerous data of the Fe/Mg interdiffusion coefficient in olivine (e.g., Buening and Buseck, 1973; Misener, 1974; Nakamura and Schmalzried, 1984; Jurewicz and Watson, 1988; Chakraborty, 1997; Dohmen and Chakraborty, 2007a,b). The validity and range of applications were extensively addressed by several authors (e.g., Weinbruch et al., 1994; Chakraborty, 2010), so we will not discuss this issue in this work. Diffusion coefficients depend on temperature, pressure, chemical composition, oxygen fugacity, crystalline defects, and crystallographic orientation (the diffusion being faster in olivine along the direction [001] than [100] and [010]) (e.g., Chakraborty, 2010; and references therein). Since we performed EBSD analyses to constrain the crystallographic 
directions along our diffusion profiles, we used here the $\mathrm{Fe} / \mathrm{Mg}$ interdiffusion coefficient defined by Dohmen and Chakraborty (2007b), which takes into account pressure, temperature, crystallographic directions, oxygen fugacity and chemical composition of olivine in the case of a quantitative point defect model. The equation of the diffusion coefficient along [100] is expressed as follows:

$$
\log D=-8.91-\frac{220000+\left(P-10^{5}\right) \times 7 \times 10^{-6}}{2.303 R T}+3\left(X_{F e}-0.1\right)
$$

where $T$ is the temperature $[\mathrm{K}], P$ the pressure $[\mathrm{Pa}], X_{F e}$ the mole fraction of the fayalite component, and $R$ the gas constant $\left[\mathrm{J} \cdot \mathrm{mol}^{-1} \cdot \mathrm{K}^{-1}\right]$. The diffusion coefficient along [010] and [001] can be obtained by the subtraction of $\log 6$ to the Eq. (4) (Dohmen and Chakraborty, 2007b).

Since CKs are highly oxidized (e.g., Geiger and Bischoff, 1995; Righter and Neff, 2007 ), oxygen fugacity was fixed at $10^{-12}$ corresponding to the NNO buffer at $\sim 1167 \mathrm{~K}$ (Huebner and Sato, 1970). The fayalite content was fixed to the value corresponding to the mean composition of forsterite from the unequilibrated core of each chondrule investigated. So, this value does not depend on the olivine composition in our model. We fixed a constant pressure at 10 bars, which approximately corresponds to the lithostatic pressure within an asteroid-sized parent body with a radius of $\sim 100 \mathrm{~km}$ (Weidenschilling and Cuzzi, 2006).

\section{Diffusion lengths}

As shown in Fig. 8, the chemical profiles measured by EPMA are well fit by the twostage diffusion model described above. The ranges of diffusion lengths estimated from the first stage of the diffusion modeling $\left(a_{1}\right)$ are 15-100 $\mu \mathrm{m}(46 \pm 27 \mu \mathrm{m})$ for $\mathrm{DaG} 431,26-65 \mu \mathrm{m}$ $(48 \pm 16 \mu \mathrm{m})$ for NWA 4724, 46-90 $\mu \mathrm{m}(65 \pm 21 \mu \mathrm{m})$ for NWA 4423, and 63-90 $\mu \mathrm{m}(72 \pm 11$ $\mu \mathrm{m})$ for Tnz 057. For the diffusion lengths inferred from the second stage of the diffusion modeling $\left(a_{2}\right)$, the ranges estimated are 6-20 $\mu \mathrm{m}(14 \pm 6 \mu \mathrm{m})$ for $\mathrm{DaG} 431,7-20 \mu \mathrm{m}(14 \pm 5$ $\mu \mathrm{m})$ for NWA 4724, 10-60 $\mu \mathrm{m}(19 \pm 14 \mu \mathrm{m})$ for NWA 4423, and 10-23 $\mu \mathrm{m}(15 \pm 5 \mu \mathrm{m})$ for Tnz 057 . The anisotropy of diffusion in olivine and section bias can easily explain the scattering of the diffusion lengths reported here.

\section{Steepest chemical profiles}

As noted above, the total duration of this two-stage diffusion modeling is calculated by the addition of the two durations inferred from the diffusion lengths estimated for each stage. The total duration (time) estimated for each chemical profile is thus mainly constrained by the first stage of our model because $a_{1}$ is significantly larger than $a_{2}$. Among the chemical profiles measured through a single olivine crystal and perpendicularly to a chondrule/matrix interface with no igneous rim and vesiculated olivine, we considered as the steepest chemical profiles those displaying the smallest values of $a_{1}$ (profile \#5 for DaG 431, \#3 for NWA 4724, \#2 for NWA 4423, and \#1 for Tnz 057) (Tables 3 and 4).

The table 4 lists, for the steepest chemical profiles measured for each sample, the parameters used for the two-stage diffusion modeling: the Fe contents measured by EPMA within chondrules $\left(C_{0}\right)$ and at the matrix/chondrule interfaces $\left(C_{1}\right)$, as well as the angles measured between the chemical profiles and crystallographic orientation of olivines. Presumed Fe contents of matrices before metamorphism $\left(C_{\mathrm{S}}\right)$ were inferred from the first stage diffusion modeling which gives values ranging between 20 and 25 at $\% \mathrm{Fe}$ in the bulk. These values correspond to olivine $\sim \mathrm{Fa}_{70}-\mathrm{Fa}_{87.5}$ considering a pure $\mathrm{Mg}_{2} \mathrm{SiO}_{4}-\mathrm{Fe}_{2} \mathrm{SiO}_{4}$ solid solution. 
For these steepest chemical profiles, the diffusion lengths obtained for the two stages of our diffusion modeling are given in Table 4. The steepest chemical profiles from DaG 4315 and Tnz 057-1 display the smallest and widest diffusion lengths, respectively. To minimize bias due to the non-equatorial sectioning of chondrules, we will only use and discuss the results obtained for these steepest chemical profiles. So, these results will give upper limits for the time-temperature conditions of the CK thermal event.

\section{Time-temperature pairs}

The Fig. 9 shows the time-temperature curves obtained for the steepest profiles measured and using the diffusion lengths presented in Table 4. At a given duration, the maximal peak metamorphic temperature increases from DaG 431 (classified as a CK3-an) to Tnz 057 (classified as a CK4). For a duration of $1 \times 10^{6}$ years, the peak metamorphic temperatures range approximately from 800 to $840 \mathrm{~K}$ for $\mathrm{DaG} 431$ and Tnz 057, respectively. If the duration of the thermal event decreases to 100 years, the peak metamorphic temperatures obtained for $\mathrm{DaG} 431$ and Tnz 057 rise to 1100 and $1190 \mathrm{~K}$, respectively.

\section{DISCUSSION}

\subsection{Modal abundances and physical properties of chondrules in CKs: similarities with chondrules in CVs}

Modal abundances of chondrules estimated here for the Kaba, Bali, Allende, and NWA 779 CV3 chondrites are consistent with the typical value reported for CVs (45\%; Scott et al., 1996). The differences between the value measured here for Allende and those determined by McSween (1977) and Ebel et al. (2008, 2009) may be attributed to the method of measurement used. However, an intrinsic heterogeneous distribution of chondrules between different thin sections cannot be excluded.

Chondrules in CK3s can be easily recognized. Indeed, they are less recrystallized than in higher petrologic types, often display Fe/Mg zonations in olivine, and sometimes contain former mesostasis recrystallized as a fine-grained mixture composed of plagioclase and pyroxene. The modal abundances of chondrules are not significantly different between CK3s $(22.1 \pm 3.5 \%)$ and CK4s $(26.5 \pm 9.0 \%)$ but decrease from CK4s to CK6s. This diminution is a consequence of the recrystallization and chemical re-equilibration of chondrules with the host matrix during metamorphism. Since the smallest chondrules initially present in the CK3-4 probably disappeared during metamorphism, the average modal abundance of chondrules in CKs would have been higher than $\sim 30 \%$. A value of $45-50 \%$ (as defined for CVs and as measured here in NWA 5733 and Maralinga) appears more appropriate to characterize the initial modal abundance of chondrules in CKs prior to metamorphism.

The mean diameters of chondrules from all CV and CK chondrites studied here are similar, from 0.31 to 0.96 and from 0.47 to $1.05 \mathrm{~mm}$, respectively. The mean diameters calculated in this study are consistent with values reported by Geiger et al. (1993), Zipfel et al. (2000), Bukovanská et al. (2003), Smith and Russell (2003), and Rubin et al. (2010) for the Watson 002, NWA 1559, and DaG 431 CK3 chondrites (mean diameters of approximately $0.90 \mathrm{~mm}$, with a maximal range of $0.16-7.5 \mathrm{~mm}$ ). These results indicate that chondrule sizes should not be used as a criterion for distinguishing between CV and CK chondrites. We can also note that sizes reported in this study can be biased due to (i) the small areas investigated for some meteorites, (ii) the non-equatorial sectioning of chondrules and (iii) the unequal 
probability of sectioning chondrules with different sizes (Eisenhour, 1996). However, they are comparable to previous studies of CV and CK chondrites for which no corrections of chondrule sizes have been realized.

Due to the chemical re-equilibration of chondrules and their recrystallization during metamorphism, it is sometimes difficult to distinguish between Type I and Type II chondrules. Since we considered for our estimations only chondrules for which we were certain that they correspond to former Type I chondrules, modal abundances presented here are underestimated. Unlike OCs, CCs (especially CVs) only contain a small amount of Type II chondrules (e.g., Zanda et al., 2006; and references therein). Even if feldspar compositions can be used for distinguishing between metamorphosed Type I and II chondrules (e.g., Huss et al., 2006; and references therein), this phase is rare in CK chondrules. Moreover, feldspar is present as a fine-grained mixture in association with pyroxene, which does not permit quantitative EPMA measurements. Thus, the initial proportions of Type I chondrules in the CK3s samples investigated and in the Tnz 057 CK4 chondrite should be closer to those measured for CVs.

The value of $15 \%$ present in literature for the modal abundance of chondrules in CKs appears to be a low estimation of the true abundance rather than a mean value. This low value of $15 \%$ is due to previous measurements realized on CK with petrologic types $>3$. Our study of numerous CKs, in particular $5 \mathrm{CK} 3 \mathrm{~s}$, points out the existence, for this group of CCs, of a large range of modal abundances of chondrules. Chondrules are partially to completely reequilibrated during metamorphism, hence the range of modal abundances measured in this work. In addition, this large range of modal abundances can cause numerous bias of classification, i.e., the systematic classification of samples with unequilibrated chondrules as CVs and samples with recrystallized matrices as CKs (see discussion in Chaumard et al., 2014). Regarding our results, a continuum between modal abundances of chondrules measured in $\mathrm{CV}$ and $\mathrm{CK}$ chondrites should be considered. In CVs, chondrules are well preserved because they have experienced minimal parent body metamorphism. With the increase of the metamorphism, chondrules progressively disappeared, as indicated by the diminution of their modal abundances from $\mathrm{CV}$ to $\mathrm{CK} 6$ chondrites. As previously suggested by Greenwood et al. (2010), Wasson et al. (2013), and Chaumard et al. (2014), the current CV and CK classification into two distinct groups should be revised to form one single group.

\subsection{Igneous rims of CK chondrules}

CK chondrules were initially defined as being free of igneous rims (Kallemeyn et al., 1991) while igneous rims are currently described as a typical feature of CV chondrules (e.g., Rubin 1984a,b; Rubin and Wasson, 1987; Rubin, 2010). Up to now, igneous rims were only described around a few chondrules from the two CK3 NWA 1559 and DaG 431 (Zipfel et al., 2000; Rubin, 2010). We reported here the occurrence of numerous chondrules surrounded by a thick igneous rim mainly composed of pyroxene, magnetite, olivine, and plagioclase in the CK3-4 chondrites DaG 431, NWA 1559, NWA 4724, NWA 4425, NWA 4423, NWA 4422, and Tnz 057. As proposed by Smith and Russell (2003), we interpret the lack of igneous rims around chondrules from $\mathrm{CK}$ chondrites with petrologic types $>4$ as a consequence of the parent body metamorphic event. These results point out that the occurrence or the lack of igneous rims around chondrules should not be used for distinguishing between $\mathrm{CV}$ and $\mathrm{CK}$ chondrites.

The occurrence of numerous igneous rims seems to indicate that some of chondrules in $\mathrm{CK}$ chondrites experienced at least two melting episodes prior to their accretion into the parent bodies. As discussed by Rubin (2010), igneous rims may have formed during a thermal 
event that caused the re-melting of a dust mantle or dustball accreted around former chondrules. This dusty material, probably similar to the dust mantles reported in primitive chondrites (e.g., McSween and Richardson, 1977; Scott et al., 1984, 1988; Alexander et al., 1989; Brearley, 1993; Brearley et al., 1995), would have been accreted in the dusty environments of the solar nebula (e.g., Zanda et al., 2002; Rubin, 2010). According to the sizes, petrology, and textural characteristics of their igneous rims, chondrules in CV, CK, as well as in CR chondrites (e.g., Rubin, 2010) may have undergone similar pre-accretionary events, hence a probable formation in a similar region of the protoplanetary disk.

\subsection{Peak metamorphic temperatures of $\mathrm{CV}$ and $\mathrm{CK}$ chondrites.}

The study of the $\mathrm{Fe} / \mathrm{Mg}$ interdiffusion in zoned olivines from unequilibrated chondrules found in CK3-4 chondrites provides time-temperature curves for each diffusion profile studied. Thus, we are able to determine different time-temperature scenarios. However, it is impossible to isolate one distinct scenario without fixing time or temperature. An accurate estimation of the peak metamorphic temperature is at least necessary to deduce the time scale of the CK thermal event.

Numerous authors estimated, using different geothermometers, the peak metamorphic temperature of the CV parent body event of 520-900 K (e.g., Kullerud and Yund, 1962; Fuchs, 1971; Brecher and Arrhenius, 1974; Blum et al., 1989; Huss and Lewis, 1994; Weinbruch et al., 1994; Krot et al., 1995; Lee et al., 1996; Huss et al., 2006; Busemann et al., 2007). Though the peak metamorphic temperature estimated for Allende globally ranges from $\sim 770$ to 870 K (e.g., Huss and Lewis, 1994; Busemann et al., 2007; Krot et al. 2007; Cody et al., 2008), some authors reported a value of around $600 \mathrm{~K}$ (Rietmeijer and MacKinnon, 1985; Bonal et al., 2007). In addition, and based on the study of Fe/Mg interdiffusion profiles in rimmed forsterite grains isolated in the Allende matrix, Cuvillier et al. (2015) proposed a peak metamorphic temperature ranging from 695 to $775 \mathrm{~K}$. Regarding this large range of estimates, the peak metamorphic temperature of $\mathrm{CV}$ chondrites is therefore not accurately known and still subject to considerable debate.

In contrast to $\mathrm{CV}$ chondrites, there are only few estimates of the peak metamorphic temperatures of CK chondrites. First, and based on the distribution of pre-solar components in Karoonda (CK4), Clayton et al. (1977) reported a peak metamorphic temperature of $\sim 800 \mathrm{~K}$. Using the method defined by Lindsley and Andersen (1983) based on the chemical composition of coexisting pyroxenes, Geiger and Bischoff (1991) estimated metamorphic temperatures in the range of $\sim 820-920 \mathrm{~K}$ for CK4, $\sim 920-1070 \mathrm{~K}$ for CK5, and $\sim 1070-1270$ $\mathrm{K}$ for CK6 chondrites. Olivine-spinel thermometry and pyroxene compositions indicate that Maralinga (CK4), Y-693 (CK4/5), EET 87507 (CK5), and some fragments of Karoonda (CK4) were heated at temperatures ranging from 1020 to $1120 \mathrm{~K}$ (Noguchi, 1993). A few years later, Clayton and Mayeda (1999) proposed a new range of metamorphic temperatures for CK4s between 860 and $900 \mathrm{~K}$, inferred from ${ }^{18} \mathrm{O} /{ }^{16} \mathrm{O}$ fractionations among major minerals. Two studies by Nakamuta et al. (2001) and Tachibana et al. (2002), who used the chemical compositions of plagioclases and pyroxenes present in Kobe (CK4), suggested a peak metamorphic temperature of $\sim 970-1070 \mathrm{~K}$ for this meteorite. Recent estimations are given by Neff and Righter (2006) and Righter and Neff (2007) who proposed, using the Fe, $\mathrm{Ti}$ geothermobarometer based on the distribution of Ti between ilmenite and magnetite (e.g., Lindsley and Andersen, 1988; Ghiorso and Sack, 1991), peak metamorphic temperatures for CKs in the range of 550-930 K. Finally, Chaumard et al. (2014) suggested, based on petrological and Al-Mg isotopic analyses of a coarse-grained CAI in Tnz 057 (CK4), a peak metamorphic temperature ranging from $\sim 810$ to $1070 \mathrm{~K}$. 
The large range of peak metamorphic temperatures estimated for CV and CK chondrites can be the consequence of uncertainties inherent to the various methods used. Indeed, they are calibrated and determined for distinct chemical compositions and ranges of temperature. For example, temperatures inferred from olivine-spinel thermometry range from 800-1000 K. As pointed out by Weinbruch et al. (1994), these temperatures, which are close to the application limit of the thermodynamic data (e.g., Fabriès, 1979; Roeder et al., 1979), presumably represent the closure temperature of the $\mathrm{Fe} / \mathrm{Mg}$ interdiffusion in olivine. As for temperatures deduced from pyroxene compositions, they should be carefully interpreted. Indeed, this method does not take into account possible significant amounts of $\mathrm{Al}_{2} \mathrm{O}_{3}$ in pyroxene, as observed in CK chondrites (0.7-3.45 wt\%; Noguchi, 1993).

With respect to our results, the lower limit of the peak metamorphic temperatures inferred from the Fe, Ti geothermobarometer used by Neff and Righter (2006) and Righter and Neff (2007) (550 K) gives unrealistic durations for the CK thermal event, i.e., $\sim 0.3$ and $1.7 \times 10^{13}$ years for DaG 431 and Tnz 057 , respectively. This result is consistent with the fact that this temperature is certainly not relevant to diffusion in silicates at the SEM scale. The temperature of $550 \mathrm{~K}$ thus appears to underestimate the true lower limit of the CK peak metamorphic temperatures. This method, which always blocks approximately $200 \mathrm{~K}$ lower than the two pyroxene geothermometer (e.g., Lindsley and Andersen, 1983), is not the best way to constrain the peak metamorphic temperatures of CV and CK chondrites.

CK3-4 contain unequilibrated pyroxenes, i.e., in Karoonda (Noguchi, 1993). The peak metamorphic temperatures estimated for the CK4s using the two-pyroxene geothermometer are thus doubtful because the samples investigated (e.g., Karoonda, Kobe) are not completely equilibrated. However, pyroxene compositions reported by Noguchi (1993) for Y-693 (CK4/5) and EET 87507 (CK5) indicate equilibrated compositions with a mixing line between orthopyroxene and augite $\left(\sim \mathrm{Wo}_{45}\right)$. Thus, and using the two-pyroxene geothermometer (Lindsley, 1983; Lindsley and Andersen, 1983), these compositions give a maximal peak temperature of $1070 \mathrm{~K}$.

In addition, pentlandite is ubiquitous in all petrologic types of CK chondrites (Geiger and Bischoff, 1995). Since this sulfide is not stable at temperatures higher than $883 \mathrm{~K}$ (e.g., Craig, 1973), it is commonly argued that CKs were not heated at temperatures exceeding $\sim 880 \mathrm{~K}$. This hypothesis considers a formation of pentlandite during prograde metamorphism rather than during cooling. However, Sugaki et al. (1982) and Sugaki and Kitakaze (1992) described the formation of a high temperature form of pentlandite at $\sim 880 \mathrm{~K}$ (isometric system, cell parameter $=5.189 \AA$ at $893 \mathrm{~K}$; Sugaki and Kitakaze, 1998). The solid solution of such pentlandite varies from $\mathrm{Fe}_{5.07} \mathrm{Ni}_{3.93} \mathrm{~S}_{7.85}$ to $\mathrm{Fe}_{3.61} \mathrm{Ni}_{5.39} \mathrm{~S}_{7.85}$ at $\sim 1125 \mathrm{~K}$. Above $\sim 1140 \mathrm{~K}$, the decomposition of this high temperature form of pentlandite into monosulfide solid solution (MSS) + liquid is observed, thus given a new plausible upper limit of the peak metamorphic temperature undergone by $\mathrm{CK}$ chondrites. Although no crystallographic investigations were realized on pentlandites in CKs so far, the compositions reported by Geiger and Bischoff (1995) can be consistent with this high temperature form.

The large temperature range of the CK metamorphic event reflects the use of different geothermometers, which possibly recorded closure temperatures rather than peak metamorphic temperatures. However, the diffusion of $\mathrm{Fe}$ in pyroxene is slower than in olivine, which is slower than in oxides. The highest estimates of the peak metamorphic temperatures of CK chondrites with petrologic types $>4$ are thus more realistic for what happened in olivine. Moreover, the presence, in igneous rims around chondrules from $\mathrm{CK}$ chondrites, of Ca-rich pyroxene grains with a texture of dehydrated phyllosilicates, is inconsistent with the lowest peak metamorphic temperatures given by previous works. As experimentally investigated by Akai (1992), the decomposition of Mg-Fe serpentine into 
olivine and enstatite starts at $570 \mathrm{~K}$ but its structure can be still observed till $1020 \mathrm{~K}$ (1070$1170 \mathrm{~K}$ for $\mathrm{Mg}$-Fe saponite). With respect to these studies, the assumption that peak metamorphic temperatures of CK chondrites range from 920 to $1140 \mathrm{~K}$ thus seems to be reasonable.

\subsection{Time scale(s) of the CK parent body metamorphism}

As discussed in the previous section, it is impossible to isolate, using the timetemperature curves reported in Fig. 9, one distinct time-temperature scenario without fixing time or temperature. Among $\mathrm{CKs}$ analyzed here using Fe/ $\mathrm{Mg}$ interdiffusion in olivine, Tnz 057 is the unique sample for which the maximal peak metamorphic temperature was estimated using the presence of grossular in CAIs (1070 K; Chaumard et al., 2014). So, we are able to calculate an accurate minimal time scale for the parent body metamorphism of this CK4 chondrite. The steepest chemical profile measured in Tnz 057 thus gives a duration of $\sim 1200$ years at $1070 \mathrm{~K}$.

The time scales inferred from the most reasonable range of peak temperatures discussed above for the $\mathrm{CK}$ metamorphic event vary between $\sim 50$ years at $1140 \mathrm{~K}$ and 70000 years at $920 \mathrm{~K}$. The time-temperature curves reported in Fig. 9 may suggest that CK chondrites were heated at various durations (between 50 and 70000 years) and temperatures (between 920 and $1140 \mathrm{~K}$ ). This scenario reflects thermal processes such as radiative heating and impacts as proposed by Chaumard et al. (2012) and Wasson et al. (2013), respectively. Using a combined study of the chemical zonations in olivine and diopside grains in Allende, Cuvillier et al. (2015) reported a peak metamorphic temperature higher than $805 \mathrm{~K}$, which corresponds to a duration shorter than $0.1 \times 10^{6}$ years. The authors concluded that these short time scales are probably due to the extrapolation of the diffusion coefficients at low temperatures. However, radiative heating and impacts can also explain such short durations.

Regarding the range of peak temperatures estimated for the CK metamorphic event (920-1140 K), we could also suppose that CKs have been heated at a given duration but at different temperatures. In this scenario, the samples were either heated for long durations at low temperatures, or for short durations at high temperatures. We obtain, for a duration of 70 000 years, peak metamorphic temperatures for CK3s ranging from 850 to $920 \mathrm{~K}$ and higher than $\sim 920 \mathrm{~K}$ for CK4-6. At a given duration of around 50 years, CK3s would have been heated at peak temperatures ranging from 1140 to $1220 \mathrm{~K}$ while peak metamorphic temperatures of CK4-6 were higher than $\sim 1220 \mathrm{~K}$. However, since CK3 chondrites contain numerous unequilibrated silicates, they were most probably not heated at temperatures higher than $\sim 1170 \mathrm{~K}$ (see section 4.3). In addition, a peak metamorphic temperature of $\sim 1220 \mathrm{~K}$ and higher is probably too high to preserve the pyroxene disequilibrium observed in CK4 chondrites. Therefore, the duration of 50 years seems to be unreasonable here.

This constant duration/different temperatures scenario is characteristic of a thermal evolution on a thermally stratified (onion-shell) parent body involving internal sources of heat such as ${ }^{26} \mathrm{Al}$ (e.g., Greenwood et al., 2010a; Weiss et al., 2010; Elkins-Tanton et al., 2011; Sahijpal and Gupta, 2011). The characteristic durations of such thermally stratified asteroids range from approximately 1 to $100 \times 10^{6}$ years (e.g., Bennett and McSween, 1996; Ghosh and McSween, 1998; McSween et al., 2002; Huss et al., 2006; Henke et al., 2013). These durations are clearly at variance with the time scales (50-70 000 years) inferred from the range of peak metamorphic temperatures estimated for CK chondrites. However, and considering a duration of $1 \times 10^{6}$ years, we obtain a peak metamorphic temperature of 800-840 $\mathrm{K}$ for $\mathrm{CK} 3$ and $>840 \mathrm{~K}$ for CK4-6. For a duration of $100 \times 10^{6}$ years, these temperatures decrease to $\sim 700-730 \mathrm{~K}$ for $\mathrm{CK} 3$ and $>730 \mathrm{~K}$ for CK4-6. 
Davidson et al. (2014) suggest, for the anomalous CK3 Watson 002, a duration of the metamorphic event of $11 \times 10^{6}$ years at $773 \mathrm{~K}$. The diffusion length of $64 \pm 25 \mu \mathrm{m}$ measured by the authors in a zoned olivine grain is consistent with the values obtained in this work from the first stage of our diffusion model $\left(a_{1}\right)$ (see section 3.3). However, Davidson et al. (2014) used a peak metamorphic temperature of $773 \mathrm{~K}$ corresponding to the lowest value determined for CO chondrites of petrologic subtype 3.5 (e.g., Busemann et al., 2007). The duration of $11 \times 10^{6}$ years inferred from this peak metamorphic temperature is thus not in agreement with the shorter time scales estimated in this work (50-70 000 years). Using a peak metamorphic temperature consistent with the most reasonable range proposed for CK chondrites $(920-1140$ $\mathrm{K})$, this duration of $11 \times 10^{6}$ years will decrease to a value lower than $\sim 70000$ years.

\subsection{Relationship between the CV and CK parent body metamorphism}

The two-stage diffusion process invoked in this work to account for the position of all inflection points implies an initial matrix olivine composition ranging from $\mathrm{Fa}_{70}-\mathrm{Fa}_{87.5}$. These presumed $\mathrm{Fa}$ contents of the matrix olivines before metamorphism are consistent with the range of compositions measured in $\mathrm{CV}$ chondrites, i.e., $\sim \mathrm{Fa}_{10}-\mathrm{Fa}_{90}$ in the Mokoia $\mathrm{CV}_{\text {OхB }}$ chondrite (e.g., Keller and Buseck, 1990; Tomeoka and Buseck, 1990; Krot et al., 1995). However, the mean value of the matrix olivine compositions in CVs is usually close to $\sim \mathrm{Fa}_{60}$. The theoretical initial Fa content of the matrix olivines inferred from our diffusion modeling thus appears to slightly overestimate the true initial composition. Nevertheless, this underestimation does not drastically modify the durations estimated here. Indeed, additional simulations were realized using an initial composition of the matrix olivines around $\mathrm{Fa}_{60}$. The results show that, at a given temperature, the durations obtained with the two-stage model developed here slightly decrease. They never increase. In term of matrix olivine compositions, CKs could thus derive from a former CV-type material that evolved during parent body metamorphism, causing the textural and chemical re-equilibration of all chondritic components.

If CKs are metamorphosed CVs, time scales and peak metamorphic temperatures inferred from $\mathrm{Fe} / \mathrm{Mg}$ interdiffusion in zoned olivines from $\mathrm{CV}$ chondrules have to be consistent with our results. Weinbruch et al. (1994), using the Fe/Mg interdiffusion coefficients defined by Buening and Buseck (1973) and Nakamura and Schmalzried (1984), suggested an upper limit of peak metamorphic temperature ranging between $600 \mathrm{~K}$ and 750 $\mathrm{K}$, respectively. However, these temperatures were arbitrarily estimated assuming a duration of $10^{6}$ years, which is a time scale characteristic of the decay of ${ }^{26} \mathrm{Al}$ as the source of heat. We reported time-temperature curves defined by Weinbruch et al. (1994) in Fig. 9. For durations of approximately 70000 years, data from Weinbruch et al. (1994) give a peak metamorphic temperature for Allende of around $\sim 680 \mathrm{~K}$ and $\sim 800 \mathrm{~K}$ using the diffusion coefficients defined by Buening and Buseck (1973) and Nakamura and Schmalzried (1984), respectively. At durations of approximately 50 years, peak metamorphic temperatures from Weinbruch et al. (1994) increase to $\sim 800$ and $\sim 960 \mathrm{~K}$ using the diffusion coefficients defined by Buening and Buseck (1973) and Nakamura and Schmalzried (1984), respectively. At a given duration, CVs would thus be heated at lower temperatures than CK chondrites. These results, consistent with the peak metamorphic temperatures estimated for Allende (695-870 K), support similar CV-CK secondary processes.

Although Weinbruch et al. (1994) preferred results obtained using the diffusion coefficient defined by Buening and Buseck (1973), we believe that data deriving from the 
diffusion coefficient defined by Nakamura and Schmalzried (1984) are more realistic. The latter was estimated using a polycrystalline material and not along the [001] crystallographic direction of olivine. The averaged value of this diffusion coefficient may be more representative of the orientation of a chemical profile randomly measured in zoned olivine. More recently, Cuvillier et al. (2013) quantified a Fe/ $\mathrm{Mg}$ interdiffusion profile measured in a forsteritic grain (possibly a fragment of a Type I chondrule) surrounded by a fayalite-rich overgrowth rim found in the matrix of Allende. The time-temperature curve reported by Cuvillier et al. (2013) is consistent with the result of Weinbruch et al. (1994) using the diffusion coefficient defined by Nakamura and Schmalzried (1984) (Fig. 9).

As pointed out by Cuvillier et al. (2013), the origin of fayalite-rich olivines around forsteritic cores in CV matrices cannot be clearly identified on the basis of these results. It would be either the consequence of parent body processes (aqueous alteration and metamorphism) as suggested by Krot et al. (2004) and Brearley (1999) or a direct condensation from the nebular gas (e.g., Weinbruch et al., 1990; Palme and Fegley, 1990; Weisberg and Prinz, 1998). Although still debated, an origin of $\mathrm{Fa}_{40-50}$ by direct condensation in the solar nebula appears unlikely regarding recent thermodynamic investigations (Grossman et al., 2012).

\subsection{Implication for the CV-CK parent body model}

Different parent body models can be considered and discussed on the basis of these results. In the model proposed by Greenwood et al. (2010a, b), CV and CK chondrites derived from a single parent body, thermally stratified, as usually invoked for OCs (e.g., Trieloff et al., 2003; Wood, 2003). The most metamorphosed lithologies (CKs) are situated in the core while the less heated ones (CVs) are at the surface of the parent body. This model implies that the durations of the parent body metamorphism were roughly similar for all CV and CK chondrites. The internal source of heat, i.e., the decay of ${ }^{26} \mathrm{Al}$, at the origin of such thermally stratified parent body gives reasonable metamorphic durations of at least $10^{6}$ years (e.g., Huss et al., 2006). With respect to our results, this period of time limits the peak metamorphic temperatures to $<800 \mathrm{~K}$ for $\mathrm{CV}, 800-840 \mathrm{~K}$ for CK3, and 840-1140 K for CK4-6 chondrites. These conditions, although not very different from those estimated by Geiger and Bischoff (1991), are at variance with the time-temperature pair reported for Tnz 057 (1200 years-1070 $\mathrm{K})$. In addition, the other possible durations estimated in this work, which are below $10^{6}$ years, are not totally consistent with a single thermally stratified CV-CK parent body. Moreover, this model also supposes that CK3 were heated at relatively low temperatures $(<840 \mathrm{~K})$. These low temperatures are poorly consistent with (i) the lack of phyllosilicates (see Akai (1992) and discussion in section 4.3) and (ii) the common association in CK3 samples of a well-recrystallized matrix (relative to CV chondrites) and unequilibrated chondrules. All these textural features are more consistent with a transient high-temperature thermal event than a parent body metamorphism caused by the decay of ${ }^{26} \mathrm{Al}$.

Recent paleomagnetic studies on CVs may indicate that the Allende CV3 chondrite could derive from the external part of a differentiated asteroid (e.g., Weiss et al., 2010; Elkins-Tanton et al., 2011; Humayun and Weiss, 2011). In this model, CKs would be located in the lower part of the undifferentiated chondritic layer situated at the surface of this parent body. As discussed above, the time-temperature conditions of such parent body that also invokes an internal source of heat are not consistent with our results. Possible metamorphic durations ranging from $\sim 50$ to 70000 years cannot be produced within an undifferentiated crust of a partially differentiated asteroid. 
Several observations are in favor of a CV-CK metamorphic event during various durations and at different temperatures. These observations are the large range of peak metamorphic temperatures estimated for CVs and CKs (see section 4.3) and the apparent lack of correlation (probably due to estimations realized from unequilibrated assemblages, i.e., in CK3-4 chondrites) between peak temperatures and petrologic types. Recently, impacts were invoked as a source of heat to explain the origin of the possible CV-CK metamorphic series (Wasson et al., 2013). In this scenario, CK were formed from CV-type materials, which were shocked, buried, affected by aqueous alteration then annealed. These parent body processes are interpreted as the cause of metamorphic events characterized by various peak metamorphic temperatures and short durations on the order of seconds to a few hundred years. Indeed, the total duration of the peak metamorphic temperature caused by shock is approximately $1 \mathrm{~s}$. (e.g., Beck et al., 2005). The duration of such thermal event can be extent to a few minutes to several hundred years due to the thermal relaxation time (e.g., Heymann, 1967; Min, 2005). For example, Miller and Wagner (1979) used zircon and apatite fission tracks from basement fragments in the impact breccia from the Ries crater to estimate the temperature-duration history of this impact structure. These authors determined that the most metamorphosed rocks were heated at $\sim 820-1070 \mathrm{~K}$ for less than one hour, whereas rocks which exhibit a peak temperature of around $470 \mathrm{~K}$ were heated for $\sim 10^{3}$ years. We can note here that metamorphic reactions at this temperature are practically ineffective. Only the lowest time scales $\left(<10^{3}\right.$ years) estimated in this work may be consistent with durations commonly assumed for a metamorphic event induced by shock. As noted by Chaumard et al. (2012) and Greenwood et al. (2010), evidence of breccias composed of CV and CK-like materials are lacking. Similarly, no polymict breccias containing CK chondrites of different petrologic types have been reported so far (though observed for OCs and Rumuruti chondrites; Bischoff et al., 2006). In consequence, we believe that impact(s) should not be considered as the most likely process that caused CV-CK metamorphism.

Another thermal process, which did not occur in a thermally stratified parent body, was proposed for CV-CK metamorphism by Chaumard et al. (2012). These authors pointed out that parent body models and sources of heat discussed above fail to account for the striking features of CK chondrites. The lack of correlation between petrologic types and shock stages and the peculiar textures of the CK4-5 matrices (e.g., Kallemeyn et al., 1991; Rubin, 1992; Tomeoka et al., 2001, 2005; Ohnishi et al., 2007; Brearley, 2009) are inconsistent with a thermally stratified parent body or a shock origin. Based on these observations, Chaumard et al. (2012) proposed an alternative parent body model based on the radiative heating of small meteoroids during close approaches to the Sun (up to $\sim 1050 \mathrm{~K}$ at perihelia $<0.15 \mathrm{AU}$ ). In this model, the intensity of this secondary thermal process is function of the size of the objects, durations for which orbits are kept stable at small perihelia, and/or heliocentric distances. This source of heat can account for (i) most of the peak metamorphic temperatures estimated for $\mathrm{CV}$ and CK chondrites, (ii) the lack of correlation between peak metamorphic temperatures and petrologic types, and (iii) durations estimated here (50-70 000 years) which are longer than what is commonly admitted for shock events (seconds; e.g., Beck et al., 2005) but shorter than what is required for nuclide decay (million years; e.g., Huss et al., 2006). Indeed, radiative heating is able to maintain temperatures sufficient for thermal metamorphism during 1 day at each revolution (Chaumard et al., 2012). Thus, and assuming an orbital period of 2 years, $\sim 1500$ years of heating time correspond to favorable orbits which are stable during $\sim 1.1 \times 10^{6}$ years. This duration is consistent with the fact that near-Earth objects with perihelion <0.1 AU can kept stable orbits up to several million years (Marchi et al., 2009; Michel and Delbo, 2010). 


\section{CONCLUSION}

The existence of a continuous CV-CK metamorphic series is reinforced by the modal abundances and sizes of chondrules, the proportion of Type I chondrules, and the occurrence of numerous igneous rims observed in the CK samples investigated. Rather than two distinct groups of carbonaceous chondrites, $\mathrm{CV}$ and $\mathrm{CK}$ chondrites are most probably derived from a common parent body. As previously proposed by Greenwood et al. (2010), Wasson et al. (2013), and Chaumard et al. (2014), CV and CK chondrites should thus be merged into a single group.

The modeling of Fe/Mg interdiffusion in zoned olivine from the DaG 431, NWA 4724, NWA 4423, and Tnz 057 CK3-4 chondrites gives, for peak metamorphic temperatures of 920-1140 K, durations varying from 50 to 70000 years. Regarding the large range of peak metamorphic temperatures estimated for CV and CK chondrites, the apparent lack of correlation between petrologic types and peak temperatures, and the time-temperature curves estimated here and for Allende (Weinbruch et al., 1994; Cuvillier et al., 2013), we suggest that $\mathrm{CV}$ and $\mathrm{CK}$ chondrites were heated at different temperatures and various durations. The durations inferred from this study (in the order of few years to hundred of thousand years), are consistent with a metamorphism caused by radiative heating. However, further estimations of the peak metamorphic temperatures of additional CK samples are needed in order to confirm this result.

\section{ACKNOWLEDGMENTS}

We gratefully thank the Muséum national d'Histoire naturelle (Paris, France) and the NASA Meteorite Working Group (Houston, Texas) for providing us CV and CK samples. We are indebted to Ariel Provost, and Eric Lewin for enlightening discussions, as well as Frédéric Béroud and Christophe Boucher for the loan of slices of Tnz 057. We thank Jean-Marc Hénot and Jean-Luc Devidal for their assistance with SEM-EBSD and EPMA, respectively. We are greatly indebted to Brigitte Zanda and Roger Hewins for helpful comments and sharing his most extensive knowledge of the petrology and mineralogy of chondrules. We are also grateful to T. Dunn, J. Davidson, and the AE, Edward R. D. Scott, as well as two anonymous reviewers for very constructive reviews and helpful comments, which led to major improvements to this manuscript.

\section{REFERENCES}

Akai J. 1992. T-T-T diagram of serpentine and saponite, and estimation of metamorphic heating degree of Antarctic carbonaceous chondrites. Proceedings of the NIPR Symposium on Antarctic Meteorites 5:120135.

Alexander C. M. O’D., Hutchison R., and Barber D. J. 1989. Origin of chondrules rims and interchondrule matrices in unequilibrated ordinary chondrites. Earth and Planetary Science Letters 95:187-207.

Beck P., Gillet P., El Goresy A., and Mostefaoui S. 2005. Timescales of shock processes in chondritic and martian meteorites. Nature 435:1071-1074. 
Bennett M. E. and McSween H. Y. Jr. 1996. Revised model calculations for the thermal histories of ordinary chondrite parent bodies. Meteoritics \& Planetary Science 31:783-792.

Bischoff A., Scott E. R. D., Metzler K., and Goodrich C. A. 2006. Nature and origins of meteoritic breccias. In Meteorites and the Early Solar System II, edited by Lauretta D. S. and McSween Jr. H. Y. Tucson, Arizona: University of Arizona Press. pp. 679-712.

Blum J. D., Wasserburg G. J., Hutcheon I. D., Beckett J. R., and Stolper E. M. 1989. Origin of opaque assemblages in $\mathrm{C} 3 \mathrm{~V}$ meteorites: Implications for nebular and planetary processes. Geochimica et Cosmochimica Acta 53:543-556.

Bonal L., Bourot-Denise M., Quirico E., Montagnac G., and Lewin E. 2007. Organic matter and metamorphic history of CO chondrites. Geochimica et Cosmochimica Acta 71:1605-1623.

Brandstätter F., Bukovanská M., and Kurat G. 2003. NWA 1559: Another anomalous CK3 chondrite (abstract)? Meteoritics \& Planetary Science 38:A63.

Brearley A. J. 1993. Matrix and fine-grained rims in the unequilibrated CO3 chondrite, ALHA77307: Origins and evidence for diverse, primitive nebular dust components. Geochimica et Cosmochimica Acta 57:1521-1550.

Brearley A. J. 1999. Origin of graphitic carbon and pentlandite in matrix olivines in the Allende meteorite. Science 285:1380-1382.

Brearley A. J. 2009. Matrix olivines in the metamorphosed CK chondrite NWA 1628: Possible affinities to olivines in the matrices of oxidized CV3 chondrites and dark inclusions (abstract \#1791). 40th Lunar and Planetary Science Conference. CD-ROM.

Brearley A. J. and Krot A. N. 2012. Metasomatism in the early Solar System: The record from chondritic meteorites. In Metasomatism and the chemical transformation of rock, edited by Harlov D. E. and Austrheim H. Lecture Notes in Earth System Sciences, Springer. pp. 659-789.

Brearley A. J., Bajt S., and Sutton S. R. 1995. Distribution of moderately volatile trace elements in fine-grained chondrule rims in the unequilibrated CO3 chondrite, ALHA77307. Geochimica et Cosmochimica Acta 59:4307-4316.

Brecher A. and Arrhenius G. 1974. The paleomagnetic record in carbonaceous chondrites: Natural remanence and magnetic properties. Journal of Geophysical Research 79:2081-2106.

Buening D. K. and Buseck P. R. 1973. Fe-Mg lattice diffusion in olivine. Journal of Geophysical Research 78:6852-6862.

Bukovanská M., Brandstätter F., and Kurat G. 2003. NWA 1560 (CK4/5) and NWA 1563 (CK5) - A comparison with $\mathrm{HaH} 280$ (CK4) chondrite (abstract). Meteoritics \& Planetary Science 38:A84.

Busemann H., Alexander C. M. O'.D., and Nittler L. R. 2007. Characterization of insoluble organic matter in primitive meteorites by microRaman spectroscopy. Meteoritics \& Planetary Science 42:1387-1416.

Chakraborty S. 1997. Rates and mechanisms of Fe-Mg interdiffusion in olivine at $980^{\circ}-1300^{\circ} \mathrm{C}$. Journal of Geophysical Research 102:12317-12332.

Chakraborty S. 2010. Diffusion coefficients in olivine, wadsleyite and ringwoodite. In Diffusion in minerals and melts, edited by Zhang Y. and Cherniak D. Reviews in Mineralogy and Geochemistry, vol. 72.

Washington D.C.: Mineralogical Society of America. pp. 603-639.

Chaumard N., Devouard B., Zanda B., and Ferrière L. 2009. The link between CV and CK carbonaceous chondrites based on parent-body processes (abstract). Meteoritics \& Planetary Science 44:A5206.

Chaumard N., Devouard B., Delbo M., Provost A., and Zanda B. 2012. Radiative heating of carbonaceous nearEarth objects as a cause of thermal metamorphism for CK chondrites. Icarus 220:65-73.

Chaumard N., Devouard B., Bouvier A., and Wadhwa M. 2014. Metamorphosed calcium-aluminum-rich inclusions in CK carbonaceous chondrites. Meteoritics \& Planetary Science 49:419-452.

Clayton R. N. and Mayeda T. K. 1999. Oxygen isotope studies of carbonaceous chondrites. Geochimica et Cosmochimica Acta 63:2089-2104.

Clayton R. N., Onuma N., Grossman L., and Mayeda T. K. 1977. Distribution of the pre-solar component in Allende and other carbonaceous chondrites. Earth and Planetary Science Letters 34:209-224.

Cody G. D., Alexander C. M. O’D., Yabuta H., Kilcoyne A. L. D., Araki T., Ade H., Dera P., Fogel M., Militzer B., and Mysen B. O. 2008. Organic thermometry for chondritic parent bodies. Earth and Planetary Science Letters 272:446-455.

Craig J. R. 1973. Pyrite-pentlandite assemblages and other low temperature relations in the Fe-Ni-S system. American Journal of Science 273A:496-510.

Crank J. 1975. The Mathematics of Diffusion. Oxford: Oxford University Press. 414 pp.

Cuvillier P., Leroux H., and Jacob D. 2013. Fe-Mg interdiffusion profiles in forsterite within the Allende matrix. Time-temperature constraints deduced from a TEM study (abstract \#1873). 44th Lunar and Planetary Science Conference. CD-ROM.

Cuvillier P., Leroux H., Jacob D., and Hirel P. (2015) Fe-Mg interdiffusion profiles in rimmed forsterite grains in the Allende matrix: Time-temperature constraints for the parent body metamorphism. Meteoritics \& 
Planetary Science 50:1529-1545.

Davidson J., Krot A. N., Nagashima K., Hellebrand E., and Lauretta D. S. 2014. Oxygen isotope and chemical compositions of magnetite and olivine in the anomalous CK3 Watson 002 and ungrouped Asuka-881595 carbonaceous chondrites: Effects of parent body metamorphism. Meteoritics \& Planetary Science 49:1456-1474.

Devouard B., Ferrière L., Zanda-Hewins B., and Messaoudi M. 2006. Mineralogy and petrology of TNZ 057 (C4) and comparison to the CV and CK groups (abstract). Meteoritics \& Planetary Science 41:A203.

Dohmen R. and Chakraborty S. 2007a. Fe-Mg diffusion in olivine II: point defect chemistry, change of diffusion mechanisms and a model for calculation of diffusion coefficients in natural olivine. Physics and Chemistry of Minerals 34:409-430.

Dohmen R. and Chakraborty S. 2007b. Fe-Mg diffusion in olivine II: point defect chemistry, change of diffusion mechanisms and a model for calculation of diffusion coefficients in natural olivine (Erratum). Physics and Chemistry of Minerals 34:597-598.

Droop G. T. R. 1987. A general equation for estimating $\mathrm{Fe}^{3+}$ concentrations in ferromagnesian silicates and oxides from microprobe analyses, using stoichiometric criteria. Mineralogical Magazine 51:431-435.

Ebel D. S., Brunner C. E., and Weisberg M. K. 2008. Multiscale abundance and size distribution of inclusions in the Allende CV3 meteorite by X-ray image analysis of slabs (abstract \#2121). 39th Lunar and Planetary Science Conference. CD-ROM.

Ebel D. S., Leftwich K., Brunner C. E., and Weisberg M. K. 2009. Abundance and size distribution of inclusions in CV 3 chondrites by X-ray image analysis (abstract \#2065). 40th Lunar and Planetary Science Conference. CD-ROM.

Eisenhour D. D. 1996. Determining chondrule size distributions from thin-section measurements. Meteoritics \& Planetary Science 31:243-248.

Elkins-Tanton L. T., Weiss B. P., and Zuber M. T. 2011. Chondrites as samples of differentiated planetesimals. Earth and Planetary Science Letters 305:1-10.

Fabriès J. 1979. Spinel-olivine geothermometry in peridotites from ultramafic complexes. Contributions to Mineralogy and Petrology 69:329-336.

Fuchs L. H. 1971. Occurrence of wollastonite, rhönite, and andradite in the Allende meteorite. American Mineralogist 56:2053-2068.

Geiger T. and Bischoff A. 1991. The CK chondrites: Conditions of parent body metamorphism (abstract). Meteoritics 26:337.

Geiger T. and Bischoff A. 1995. Formation of opaque minerals in CK chondrites. Planetary and Space Science 43:485-498.

Geiger T., Spettel B., Clayton R. N., Mayeda T. K., and Bischoff A. 1993. Watson 002 - The first CK/Type 3 chondrite (abstract). Meteoritics 28:352.

Ghiorso M. and Sack R. O. 1991. Fe-Ti oxide geothermometry: thermodynamic formulation and the estimation of intensive variables in silicic magmas. Contributions to Mineralogy and Petrology 108:485-510.

Ghosh A. and McSween H. Y. 1998. A thermal model for the differentiation of asteroid 4 Vesta, based on radiogenic heating. Icarus 134:187-206.

Greenwood R. C., Kearsley A. T., and Franchi I. A. 2003. Are CK chondrites really a distinct group or just equilibrated CVs (abstract)? Meteoritics \& Planetary Science 35:A5179.

Greenwood R. C., Franchi I. A., Kearsley A. T., and Alard O. 2004. The relationship between CK and CV chondrites: A single parent body source (abstract \#1664)? 35th Lunar and Planetary Science Conference. CD-ROM.

Greenwood R. C., Franchi I. A., Kearsley A. T., and Alard O. 2010a. The relationship between CK and CV chondrites. Geochimica et Cosmochimica Acta 74:1684-1705.

Greenwood R. C., Franchi I. A., Chaumard N., Devouard B., and Burbine T. H. 2010b. Is the Eos family derived from the breakup of a stratified CV-CK parent body (abstract)? Meteoritics \& Planetary Science 45:A5430.

Grossman L., Fedkin A. V., and Simon S. B. 2012. Formation of the first oxidized iron in the solar system. Meteoritics \& Planetary Science 47:2160-2169.

Huebner J. S. and Sato M. 1970. The oxygen fugacity-temperature relationships of maganese oxide and nickel oxide buffers. American Mineralogist 55:934-952.

Henke S., Gail H.-P., Trieloff M., and Schwartz W. H. 2013. Thermal evolution model for the H chondrite asteroid-instantaneous formation versus protracted accretion. Icarus 226:212-228.

Heymann D. 1967. On the origin of hypersthene chondrites: Ages and shock effects of black chondrites. Icarus 6:189-221.

Humayun M. and Weiss B. P. 2011. A common parent body for Eagle Station pallasites and CV chondrites (abstract \#1507). 42nd Lunar and Planetary Science Conference. CD-ROM.

Huss G. R. and Lewis R. S. 1994. Noble gases in presolar diamonds II: Component abundances reflect thermal 
processing. Meteoritics 29:811-829.

Huss G. R., Rubin A. E., and Grossman J. N. 2006. Thermal metamorphism in chondrites. In Meteorites and the Early Solar System II, edited by Lauretta D. S. and McSween Jr. H. Y. Tucson, Arizona: University of Arizona Press. pp. 567-586.

Jurewicz A. J. G. and Watson E. B. 1988. Cations in olivine, Part 2: Diffusion in olivine xenocrysts, with applications to petrology and mineral physics. Contributions to Mineralogy and Petrology 99:186-201.

Kallemeyn G. W., Rubin A. E., and Wasson J. T. 1991. The compositional classification of chondrites: V - The Karoonda (CK) group of carbonaceous chondrites. Geochimica et Cosmochimica Acta 55:881-892.

Keller L. P. and Buseck P. R. 1990. Aqueous alteration in the Kaba CV3 carbonaceous chondrite. Geochimica et Cosmochimica Acta 54:2113-2120.

Keller L. P., Clark J. C., Lewis C. F., and Moore C. B. 1992. Maralinga, a metamorphosed carbonaceous chondrite found in Australia. Meteoritics 27:87-91.

Krot A. N., Scott E. R. D., and Zolensky M. E. 1995. Mineralogical and chemical modification of components in CV3 chondrites: Nebular or asteroidal processing? Meteoritics 30:748-775.

Krot A. N., Petaev M. I., and Bland P. A. 2004. Multiple formation mechanisms of ferrous olivine in CV carbonaceous chondrites during fluid-assisted metamorphism. Antarctic Meteorite Research 17:153-171.

Krot A. N., Yurimoto H., Hutcheon I. D., Libourel G., Chaussidon M., Tissandier L., Petaev M. I., MacPherson G. J., Paque-Heather J., and Wark D. 2007. Type C Ca, Al-rich inclusions from Allende: Evidence for multistage formation. Geochimica et Cosmochimica Acta 71:4342-4364.

Kullerud G. and Yund R. A. 1962. The Ni-S system and related minerals. Journal of Petrology 3:126-175.

Lee M. R., Hutchinson R., and Graham A. L. 1996 Aqueous alteration in the matrix of the Vigarano (CV3) carbonaceous chondrite. Meteoritics 31:477-483.

Lindsley D. H. 1983. Pyroxene thermometry. American Mineralogist 68:477-493.

Lindsley D. H. and Andersen D. J. 1983. A two-pyroxene thermometer. Journal of Geophysical Research 88:A887-A906.

Lindsley D. H. and Andersen D. J. 1988. Internally consistent solution models for Fe-Mg-Mn-Ti oxides: Fe-Ti oxides. American Mineralogist 73:714-726.

Marchi S., Delbo M., Morbidelli A., Paolicchi P., and Lazzarin M. 2009. Heating of near-Earth objects and meteoroids due to close approaches to the Sun. Monthly Notices of the Royal Astronomical Society 400:147-153.

McSween H. Y. 1977. Petrographic variations among carbonaceous chondrites of the Vigarano type. Geochimica et Cosmochimica Acta 41:1777-1790.

McSween H. Y. 1979. Are carbonaceous chondrites primitive or processed? A review. Reviews of Geophysics and Space Physics 17:1059-1078.

McSween H. Y. and Richardson S. M. 1977. The composition of carbonaceous chondrite matrix. Geochimica et Cosmochimica Acta 41:1145-1161.

McSween H. Y., Ghosh A., Grimm R. E., Wilson L., and Young E. D. 2002. Thermal evolution models of asteroids. In Asteroids III, edited by Bottke W. F., Cellino A., Paolicchi P., and Binzel R. P. Tucson, Arizona: University of Arizona Press. pp. 559-571.

Merli M., Oberti R., Caucia F., and Ungaretti L. 2001. Determination of site population in olivine: Warnings on X-ray data treatment and refinement. American Mineralogist 85:55-65.

Michel P. and Delbo M. 2010. Orbital and thermal evolutions of four potential targets for a sample return space mission to a primitive near-Earth asteroid. Icarus 209:520-534.

Miller D. S. and Wagner G. A. 1979. Age and intensity of thermal events by fission track analysis: The Ries impact crater. Earth and Planetary Science Letters 43:351-358.

Min K. 2005. Low-temperature thermochronology of meteorites. In Low-temperature thermochronology: Techniques, Interpretations, and Applications, edited by Reiners P. W. and Ehlers T. A. Reviews in Mineralogy and Geochemistry, vol. 58. Washington D.C.: Mineralogical Society of America. pp. 567588.

Misener D. J. 1974. Cationic diffusion in olivine $1400^{\circ} \mathrm{C}$ and 35 kbar. In Geochemical Transport and Kinetics, edited by Hoffmann A. W., Giletti B. J., Yoder H. S., and Yund R. A. Washington D.C.: Carnegie Institution of Washington. pp. 117-129.

Nakamura A. and Schmalzried H. 1984. On the $\mathrm{Fe}^{2+}-\mathrm{Mg}^{2+}$ interdiffusion in olivine (II). Berichte der Bunsengesellschaft für Physikalische Chemie 88:140-145.

Nakamuta Y., Nakamura T., and Nakamura N. 2001. Metamorphic temperature of Kobe meteorite estimated by the plagioclase thermometer (abstract). Antarctic Meteorites 26:98-100.

Neff K. E. and Righter K. 2006. Opaque assemblages in CK and CV carbonaceous chondrites (abstract \#1320). 37th Lunar and Planetary Science Conference. CD-ROM.

Noguchi T. 1993. Petrology and mineralogy of CK chondrites: Implications for the metamorphism of the CK chondrite parent body. Proceedings of the NIPR Symposium on Antarctic Meteorites 6:204-233. 
Ohnishi I., Tomeoka K., and Ishizaki N. 2007. Microinclusion-rich vesicular olivine in the Karoonda CK4 chondrite: transmission electron microscopy. Journal of Mineralogical and Petrological Sciences 102:346-351.

Palme H. and Fegley B. Jr. 1990. High-temperature condensation of iron-rich olivine in the solar nebula. Earth and Planetary Science Letters 101:180-195.

Philibert J. 1985. Diffusion et transport de matière dans les solides [in french]. Paris: Les éditions de physique. $472 \mathrm{pp}$.

Pratesi G., Salvadori A., Moggi-Cecchi V., Franchi I., and Greenwood R. C. 2006. A new CK carbonaceous chondrite from Hammada Al Hamra, Libya (abstract \#1899). 37th Lunar and Planetary Science Conference. CD-ROM.

Rietmeijer F. and MacKinnon I. 1985. Poorly graphitized carbon as a new cosmothermometer for primitive extraterrestrial materials. Nature 315:733-736.

Righter K. and Neff K. E. 2007. Temperature and oxygen fugacity constraints on CK and R chondrites and implications for water and oxidation in the early solar system. Polar Science 1:25-44.

Roeder P. L., Campbell I. H., and Jamieson H. E. 1979. A re-evaluation of the olivine-spinel geothermometer. Contributions to Mineralogy and Petrology 68:325-334.

Rubin A. E. 1984a. Coarse-grained chondrule rims in type 3 chondrites. Geochimica et Cosmochimica Acta 48:1779-1789.

Rubin A. E. 1984b. Manganiferous orthopyroxene and olivine in the Allende meteorite. American Mineralogist 69:880-888.

Rubin A. E. 1992. A shock-metamorphic model for silicate darkening and compositionally variable plagioclase in CK and ordinary chondrites. Geochimica et Cosmochimica Acta 56:1705-1714.

Rubin A. E. 2010. Physical properties of chondrules in different chondrite groups: Implications for multiple melting events in dusty environments. Geochimica et Cosmochimica Acta 74:4807-4828.

Rubin A. E. and Wasson J. T. 1987. Chondrules, matrix and coarse-grained chondrule rims in the Allende meteorite: Origin, interrelationships and possible precursor components. Geochimica et Cosmochimica Acta 51:1923-1937.

Sahijpal S. and Gupta G. 2011. Did the carbonaceous chondrites evolve in the crustal regions of partially differentiated asteroids? Journal of Geophysical Research 116:E06004.

Scott E. R. D. and Taylor G. J. 1985. Petrology of types 4-6 carbonaceous chondrites. Proceedings Lunar and Planetary Science 15:C699-C709.

Scott E. R. D., Rubin A. E., Taylor G. J., and Keil. K. 1984. Matrix material in type 3 chondrites - occurrence, heterogeneity and relationship with chondrules. Geochimica et Cosmochimica Acta 48:1741-1757.

Scott E. R. D., Barber D. J., Alexander C. M. O’D., Hutchison R., and Peck J. A. 1988. Primitive material surviving in chondrites: matrix. In Meteorites and the Early Solar System, edited by Kerridge J. F. and Matthews M.S. Tucson, Arizona: University of Arizona Press. pp. 718-745.

Scott E. R. D., Love S. G., and Krot A. N. 1996. Formation of chondrules and chondrites in the protoplanetary nebula. In Chondrules and the Protoplanetary Disk, edited by Hewins R. H., Jones R. H., and Scott E. R. D. Cambridge, UK: Cambridge University Press. pp. 87-96.

Smith C. L. and Russell S. S. 2003. Dar Al Gani 431: Unravelling nebular and parent body processes (abstract). Meteoritics \& Planetary Science 38:A5222.

Sugaki A., Kitakaze A., and Hayashi T. 1982. High-temperature form of pentlandite [in japanese] (abstract). Annual Meeting of the Mineralogical Society of Japan, 22 p.

Sugaki A. and Kitakaze A. 1992. Phase transition of pentlandite (abstract). 29th Internatational Geological Congress, vol. 3.676 p.

Sugaki A. and Kitakaze A. 1998. High form of pentlandite and its thermal stability. American Mineralogist 83:133-140.

Tachibana Y., Kitamura M., Hirajima T., and Nakamura N. 2002. Equilibration temperature of the Kobe meteorite. Geochemical Journal 36:323-332.

Tomeoka Y. and Buseck P. R. 1990. Phyllosilicates in the Mokoia CV carbonaceous chondrite: Evidence for aqueous alteration in an oxidizing condition. Geochimica et Cosmochimica Acta 54:1745-1754.

Tomeoka K., Ohnishi I., and Nakamura N. 2001. Silicate darkening in the Kobe CK Chondrite: Evidence for shock metamorphism at high temperature. Meteoritics \& Planetary Science 36:1535-1545.

Tomeoka K., Kojima T., Ohnishi I., Ishii Y., and Nakamura N. 2005. The Kobe CK carbonaceous chondrite: petrography, mineralogy and metamorphism. Journal of Mineralogical and Petrological Sciences 100:116-125.

Trieloff M., Jessberger E. K., Herrwerth I., Hopp J., Fiéni C., Ghélis M., Bourot-Denise M., and Pellas P. 2003. Structure and thermal history of the H-chondrite parent asteroid revealed by thermochronometry. Nature 422:502-506. 
Wasson J. T., Isa J., and Rubin A. E. 2013. Compositional and petrographic similarities of CV and CK chondrites: A single group with variations in textures and volatile concentrations attributable to impact heating, crushing and oxidation. Geochimica et Cosmochimica Acta 108:45-62.

Weidenschilling S. J. and Cuzzi J. N. 2006. Accretion dynamics and timescales: Relation to chondrites. In Meteorites and the Early Solar System II, edited by Lauretta D. S. and McSween Jr. H. Y. Tucson, Arizona. University of Arizona Press. pp. 473-485.

Weinbruch S., Palme H., Müller W. F., and El Goresy A. 1990. FeO-rich rims and veins in Allende forsterite : Evidence for high temperature condensation at oxidizing conditions. Meteoritics \& Planetary Science 25:115-125.

Weinbruch S., Armstrong J., and Palme H. 1994. Constraints on the thermal history of the Allende parent body as derived from olivine-spinel thermometry and $\mathrm{Fe} / \mathrm{Mg}$ interdiffusion in olivine. Geochimica et Cosmochimica Acta 58:1019-1030.

Weisberg M. K. and Prinz M. 1998. Fayalitic olivine in CV3 chondrite matrix and dark inclusions: A nebular origin. Meteoritics \& Planetary Science 33:1087-1099.

Weisberg M. K., McCoy T. J., and Krot A. N. 2006. Systematics and Evaluation of Meteorite Classification. In Meteorites and the Early Solar System II edited by Lauretta D. S. and McSween Jr. H. Y. Tucson, Arizona. University of Arizona Press. pp. 19-52.

Weiss B. P., Carporzen L., Elkins-Tanton L. T., Shuster D. L., Ebel D. S., Gattacceca J., Zuber M. T., Chen J. H., Papanastassiou D. A., Binzel R. P., Rumble D., and Irving A. J. 2010. A partially differentiated body for CV chondrites (abstract \#1688)? 41st Lunar and Planetary Science Conference. CD-ROM.

Wood J. A. 2003. Planetary science: Of asteroids and onions. Nature 422:479-481.

Zanda B., Bourot-Denise M., Hewins R. H., Cohen B. A., Delaney J. S., Humayun M., and Campbell A. J. 2002. Accretion textures, iron evaporation and re-condensation in Renazzo chondrules (abstract \#1852). 33th Lunar and Planetary Science Conference.

Zanda B., Hewins R. H., Bourot-Denise M., Bland P. A., and Albarède F. 2006. Formation of solar nebula reservoirs by mixing chondritic components. Earth and Planetary Science Letters 248:650-660.

Zipfel J., Palme H., Clayton R. N., Mayeda T. K., Spettel B., and Wolf D. 2000. Dar Al Gani 431: A New Anomalous CK3 Chondrite (abstract \#1668)? 31st Lunar and Planetary Science Conference. 


\section{Tables}

Table 1: List of CV and CK carbonaceous chondrites studied in this work.

\begin{tabular}{|c|c|c|c|c|c|}
\hline Meteorite name & Abbreviation & Group & Collection & Number & Support \\
\hline Kaba & - & CV3 Ox. & MNHN & - & polished section \\
\hline Bali & - & CV3 Ox. & MNHN & - & polished section \\
\hline Allende & - & CV3 Ox. & MNHN & - & scans, thick section \\
\hline Northwest Africa 2900 & NWA 2900 & $\mathrm{CV} 3 *$ & $\mathrm{BD}$ & - & polished sections, slices, thin section \\
\hline Northwest Africa 779 & NWA 779 & CV3 & $\mathrm{BD}$ & - & polished sections, slices \\
\hline Dar al Gani 431 & DaG 431 & CK3-an & MNHN & - & thin section \\
\hline Northwest Africa 1559 & NWA 1559 & CK3 & $\mathrm{BD}$ & - & thick section \\
\hline Northwest Africa 4724 & NWA 4724 & CK3.8 & MNHN & (C2006-11) & polished section \\
\hline Northwest Africa 4425 & NWA 4425 & CK3.8 & $\mathrm{MNHN}+\mathrm{BD}$ & (C2006-19) & scans, polished section, slices \\
\hline Northwest Africa 4423 & NWA 4423 & CK3.9 & MNHN & (C2006-13) & polished section \\
\hline Northwest Africa 4770 & NWA 4770 & CK4 & MNHN & - & slices \\
\hline Northwest Africa 4422 & NWA 4422 & CK4 & MNHN & (C2006-12) & polished section \\
\hline Northwest Africa 5733 & NWA 5733 & CK4 & MNHN & - & polished section \\
\hline Northwest Africa 2519 & NWA 2519 & CK4 & MNHN & - & polished section \\
\hline Karoonda & - & CK4 & MWG/NASA & $(3970-1)$ & thin section \\
\hline Kobe & - & CK4 & MWG/NASA & P4-2 & thin section \\
\hline Maralinga & - & CK4 & MNHN & - & thin section \\
\hline Tanezrouft 057 & Tnz 057 & CK4 & $\mathrm{MNHN}+\mathrm{BD}$ & - & polished sections, thick section, slices \\
\hline Northwest Africa 765 & NWA 765 & CK4/5 & MNHN & (3777 LMT28) & polished section \\
\hline Pecora Escarpment 82500 & PCA 82500 & CK4/5 & MWG/NASA & - & thin section \\
\hline Elephant Moraine 90007 & EET 90007 & CK5 & MWG/NASA & - & thin section \\
\hline Elephant Moraine 87860 & EET 87860 & CK5/6 & MWG/NASA & - & thin section \\
\hline Lewis Cliff 87009 & LEW 87009 & CK6 & MWG/NASA & - & thin section \\
\hline
\end{tabular}

$\mathrm{BD}=$ Bertrand Devouard. MNHN = Muséum national d'Histoire naturelle, Paris. MWG = NASA Meteorite Working Group, Houston.

*Although classified as a CV3 chondrite, the samples obtained from Stefan Ralew (main mass holder) are largely reequilibrated and display a well-recrystallized matrix similar to Tnz 057. 
Table 2: Abundances, types, and sizes of chondrules in CV and CK carbonaceous chondrites investigated in this study.

\begin{tabular}{|c|c|c|c|c|c|c|c|}
\hline & Type & $\begin{array}{l}\text { Studied area } \\
\qquad\left(\mathrm{cm}^{2}\right)\end{array}$ & $\begin{array}{c}\text { Total } \\
\text { chondrules } \\
(\text { area } \%)\end{array}$ & $\begin{array}{c}\text { Type I } \\
\text { chondrules } \\
(\text { area\%) }\end{array}$ & $\begin{array}{l}\text { Number of } \\
\text { chondrules }\end{array}$ & $\begin{array}{c}\text { Chondrule } \\
\text { mean diameter } \\
(\mathrm{mm})\end{array}$ & $\begin{array}{c}\text { Range of } \\
\text { chondrule } \\
\text { diameters }(\mathrm{mm})\end{array}$ \\
\hline & Mean CV $^{1}$ & & 45.0 & & & 1.0 & \\
\hline Kaba & CV3 Ox. & 0.75 & 55.7 & $\overline{0}$ & 218 & 0.31 & $0.04-2.72$ \\
\hline Bali & CV3 Ox. & 1.83 & 44.7 & $0^{\S}$ & 393 & 0.34 & $0.04-2.96$ \\
\hline Allende & CV3 Ox. & 9.20 & 37.6 & $0^{\S}$ & 498 & 0.74 & $0.15-3.17$ \\
\hline NWA 779 & CV3 & 12.15 & $39.1(1.2)$ & n.c. & 962 & $0.67(0.22)$ & $0.05-4.28$ \\
\hline NWA 2900 & CV3* & 25.56 & $18.5(3.8)$ & n.c. & 408 & $0.96(0.07)$ & $0.17-3.31$ \\
\hline$\overline{\mathrm{DaG}} \overline{4} \overline{31}--$ & $\overline{\mathrm{CK}} \overline{3}-$ & $\overline{2} . \overline{41}$ & $\overline{2} \overline{4} .9^{--}$ & $\overline{11.8}$ & $\overline{123}$ & $\overline{0} . \overline{6} \overline{2}^{--}$ & $0 . \overline{12-3} . \overline{6} \overline{7}^{--}$ \\
\hline NWA 1559 & CK3 & 1.86 & 25.7 & 12.2 & 70 & 0.79 & $0.25-3.27$ \\
\hline NWA 4724 & CK3.8 & 2.28 & $22.5(6.0)$ & $8.6(5.9)$ & 76 & $0.81(0.10)$ & $0.27-2.90$ \\
\hline NWA 4425 & CK3.8 & 25.24 & $17.1(2.7)$ & 14.4 & 368 & $1.04(0.06)$ & $0.26-3.86$ \\
\hline NWA 4423 & CK3.9 & 1.93 & 20.3 & 11.3 & 61 & 0.85 & $0.26-1.67$ \\
\hline NWA 4770 & CK4 & 7.29 & 25.1 & n.c. & 612 & 0.51 & $0.12-2.47$ \\
\hline NWA 4422 & CK4 & 2.37 & 22.8 & n.c. & 83 & 0.78 & $0.22-3.46$ \\
\hline NWA 5733 & CK4 & 1.31 & 45.0 & n.c. & 132 & 0.62 & $0.16-2.83$ \\
\hline NWA 2519 & CK4 & 1.41 & 19.1 & n.c. & 60 & 0.70 & $0.27-1.71$ \\
\hline Karoonda & CK4 & 2.54 & 28.5 & n.c. & 1029 & $0.22^{\dagger}$ & $0.08-2.17^{\dagger}$ \\
\hline Kobe & CK4 & 0.56 & 26.7 & n.c. & 30 & 0.70 & $0.12-1.71$ \\
\hline Maralinga & CK4 & 4.05 & 50.5 & n.c. & 830 & 0.47 & $0.11-2.65$ \\
\hline Tnz 057 & CK4 & 893.00 & $18.2(1.2)$ & $9.6(2.5)$ & 7313 & $1.05(0.05)$ & $0.11-5.90$ \\
\hline NWA 765 & $\mathrm{CK} 4 / 5$ & 1.76 & 14.9 & n.c. & 91 & 0.50 & $0.15-2.14$ \\
\hline PCA 82500 & $\mathrm{CK} 4 / 5$ & 0.42 & 10.7 & n.c. & 13 & 0.64 & $0.30-1.13$ \\
\hline EET 90007 & CK5 & 1.25 & 20.0 & n.c. & 39 & 0.70 & $0.22-3.60$ \\
\hline EET 87860 & CK5/6 & 0.27 & 13.0 & n.c. & 15 & 0.88 & $0.50-1.60$ \\
\hline \multirow[t]{2}{*}{ LEW 87009} & CK6 & 0.77 & 0.0 & n.c. & 0 & - & - \\
\hline & Mean $\mathrm{CK}^{1}$ & & 15 & & & 0.70 & \\
\hline
\end{tabular}

Values in parentheses correspond to 1 sigma standard deviations obtained when several sections of the same meteorite were analyzed.

* See legend in Table 1.

${ }^{1}$ Data from Scott et al. (1996).

${ }^{\S}$ See Zanda et al. (2006).

'Sizes reported here include chondrule fragments. n.c.: not calculated. 
Table 3: Chemical compositions of olivine in the core and at the borders of unequilibrated chondrules (either composed of barred, euhedral, or anhedral olivine grains) and large isolated grains for all zoning profiles measured in DaG 431, NWA 4724, NWA 4423, and Tnz 057.

\begin{tabular}{|c|c|c|c|c|c|c|c|c|c|c|c|c|}
\hline \multirow{3}{*}{$\begin{array}{l}\text { Profile \# } \\
\text { DaG } 431\end{array}$} & \multicolumn{2}{|c|}{$\# 1$} & \multicolumn{2}{|c|}{$\# 2$} & \multicolumn{2}{|c|}{$\# 3$} & \multicolumn{2}{|c|}{$\# 4$} & \multicolumn{2}{|c|}{$\# 5$} & \multicolumn{2}{|c|}{$\# 6$} \\
\hline & \multicolumn{2}{|c|}{ Isolated olivine } & \multicolumn{2}{|c|}{ Barred olivine } & \multicolumn{2}{|c|}{ Euhedral olivine } & \multicolumn{2}{|c|}{ Anhedral olivine } & \multicolumn{2}{|c|}{ Isolated olivine } & \multicolumn{2}{|c|}{ Anhedral olivine } \\
\hline & Core & Border & Core & Border & Core & Border & Core & Border & Core & Border & Core & Border \\
\hline$\overline{\mathrm{FeO}}$ & 0.56 & 29.16 & 4.89 & 27.90 & 12.21 & 24.72 & 3.47 & 27.87 & 0.81 & 27.93 & 4.83 & 28.78 \\
\hline $\mathrm{Fe} 2 \mathrm{O} 3$ & n.c. & n.c. & n.c. & n.c. & n.c. & n.c. & n.c. & n.c. & n.c. & n.c. & n.c. & n.c. \\
\hline $\mathrm{SiO} 2$ & 42.24 & 36.91 & 41.55 & 36.83 & 39.78 & 37.51 & 41.93 & 36.81 & 41.84 & 36.41 & 41.43 & 36.66 \\
\hline $\mathrm{Al} 2 \mathrm{O} 3$ & 0.12 & 0.04 & 0.03 & 0.01 & 0.29 & 0.05 & 0.22 & 0.05 & 0.32 & 0.11 & 0.15 & 0.04 \\
\hline $\mathrm{CaO}$ & 0.45 & 0.11 & 0.18 & 0.09 & 0.05 & 0.04 & 0.56 & 0.05 & 0.78 & 0.32 & 0.12 & 0.06 \\
\hline $\mathrm{MgO}$ & 55.35 & 32.01 & 51.67 & 33.18 & 46.33 & 35.97 & 53.45 & 33.26 & 54.82 & 32.38 & 52.21 & 32.22 \\
\hline $\mathrm{Cr} 2 \mathrm{O} 3$ & 0.06 & 0.05 & 0.05 & 0.02 & 0.47 & 0.06 & 0.12 & 0.07 & 0.07 & 0.08 & 0.19 & 0.04 \\
\hline $\mathrm{MnO}$ & 0.02 & 0.20 & 0.04 & 0.22 & 0.10 & 0.21 & 0.01 & 0.20 & 0.02 & 0.21 & 0.03 & 0.24 \\
\hline $\mathrm{NiO}$ & 0.02 & 0.29 & 0.05 & 0.22 & 0.03 & 0.30 & n.d. & 0.27 & n.d. & 0.25 & 0.01 & 0.26 \\
\hline Total & 98.82 & 98.77 & 98.46 & 98.48 & 99.26 & 98.84 & 99.75 & 98.57 & 98.65 & 97.67 & 98.95 & 98.30 \\
\hline \multicolumn{13}{|c|}{ Cation number in the basis of 4 oxygens } \\
\hline $\mathrm{Fe} 2+$ & 0.011 & 0.666 & 0.099 & 0.635 & 0.255 & 0.552 & 0.069 & 0.634 & 0.016 & 0.642 & 0.098 & 0.659 \\
\hline $\mathrm{Fe} 3+$ & - & - & - & - & - & - & - & - & - & - & - & - \\
\hline $\mathrm{Si}$ & 1.004 & 1.007 & 1.010 & 1.002 & 0.994 & 1.001 & 1.001 & 1.001 & 0.999 & 1.001 & 1.002 & 1.004 \\
\hline $\mathrm{Al}$ & 0.003 & 0.001 & 0.001 & 0.000 & 0.009 & 0.001 & 0.006 & 0.001 & 0.009 & 0.004 & 0.004 & 0.001 \\
\hline $\mathrm{Ca}$ & 0.012 & 0.003 & 0.005 & 0.003 & 0.001 & 0.001 & 0.014 & 0.001 & 0.020 & 0.009 & 0.003 & 0.002 \\
\hline $\mathrm{Mg}$ & 1.962 & 1.302 & 1.872 & 1.346 & 1.726 & 1.430 & 1.902 & 1.348 & 1.951 & 1.327 & 1.882 & 1.316 \\
\hline $\mathrm{Cr}$ & 0.001 & 0.001 & 0.001 & 0.000 & 0.009 & 0.001 & 0.002 & 0.001 & 0.001 & 0.002 & 0.004 & 0.001 \\
\hline $\mathrm{Mn}$ & 0.000 & 0.005 & 0.001 & 0.005 & 0.002 & 0.005 & 0.000 & 0.005 & 0.000 & 0.005 & 0.001 & 0.006 \\
\hline $\mathrm{Ni}$ & 0.000 & 0.006 & 0.001 & 0.005 & 0.001 & 0.006 & 0.000 & 0.006 & 0.000 & 0.005 & 0.000 & 0.006 \\
\hline$\sum$ cations & 2.994 & 2.992 & 2.989 & 2.997 & 2.997 & 2.998 & 2.995 & 2.998 & 2.996 & 2.996 & 2.994 & 2.995 \\
\hline \multicolumn{13}{|c|}{$\mathrm{Fe} /(\mathrm{Fe}+\mathrm{Mg})$ ratio $($ in $\%)$} \\
\hline & 0.57 & 33.82 & 5.05 & 32.06 & 12.88 & 27.83 & 3.52 & 31.98 & 0.82 & 32.61 & 4.93 & 33.39 \\
\hline
\end{tabular}

$\mathrm{Fe}^{2+}(\mathrm{FeO})$ and $\mathrm{Fe}^{3+}\left(\mathrm{Fe}_{2} \mathrm{O}_{3}\right)$ contents were estimated using the method developed by Droop (1987) based on stoichiometric criteria.

Element detection limits (in wt\%): Fe: 0.06; Si: 0.03; Al: 0.02; Ca: 0.04; Mg: 0.02; Cr: 0.03; Mn: 0.06; Ni: 0.04 . n.d.: not detected. n.c.: not calculated. 
Table 3 (continue):

\begin{tabular}{|c|c|c|c|c|c|c|c|c|}
\hline \multirow{3}{*}{$\begin{array}{l}\text { Profile \# } \\
\text { NWA } 4724\end{array}$} & \multicolumn{2}{|c|}{$\# 1$} & \multicolumn{2}{|c|}{$\# 2$} & \multicolumn{2}{|c|}{$\# 3$} & \multicolumn{2}{|c|}{$\# 4$} \\
\hline & \multicolumn{2}{|c|}{ Anhedral olivine } & \multicolumn{2}{|c|}{ Anhedral olivine } & \multicolumn{2}{|c|}{ Anhedral olivine } & \multicolumn{2}{|c|}{ Anhedral olivine } \\
\hline & Core & Border & Core & Border & Core & Border & Core & Border \\
\hline $\mathrm{FeO}$ & 0.36 & 25.98 & 10.52 & 26.43 & 0.27 & 28.06 & 6.85 & 27.09 \\
\hline $\mathrm{Fe} 2 \mathrm{O} 3$ & 0.11 & 0.34 & 0.48 & 0.00 & 0.59 & 0.15 & 0.00 & 0.00 \\
\hline $\mathrm{SiO} 2$ & 42.52 & 37.53 & 40.50 & 37.60 & 42.35 & 37.31 & 41.38 & 37.58 \\
\hline $\mathrm{Al} 2 \mathrm{O} 3$ & 0.24 & 0.07 & 0.10 & 0.24 & 0.26 & 0.09 & 0.15 & 0.05 \\
\hline $\mathrm{CaO}$ & 0.61 & 0.19 & 0.16 & 0.35 & 0.69 & 0.04 & 0.42 & 0.08 \\
\hline $\mathrm{MgO}$ & 56.53 & 35.47 & 48.36 & 34.83 & 56.34 & 34.08 & 51.40 & 34.91 \\
\hline $\mathrm{Cr} 2 \mathrm{O} 3$ & 0.08 & 0.06 & 0.18 & 0.14 & 0.08 & 0.03 & 0.18 & 0.04 \\
\hline $\mathrm{MnO}$ & n.d. & 0.18 & 0.11 & 0.26 & n.d. & 0.22 & 0.03 & 0.23 \\
\hline $\mathrm{NiO}$ & 0.01 & 0.26 & 0.04 & 0.25 & n.d. & 0.25 & 0.03 & 0.28 \\
\hline Total & 100.45 & 100.07 & 100.44 & 100.10 & 100.58 & 100.24 & 100.44 & 100.28 \\
\hline \multicolumn{9}{|c|}{ Cation number in the basis of 4 oxygens } \\
\hline $\mathrm{Fe} 2+$ & 0.007 & 0.577 & 0.216 & 0.587 & 0.005 & 0.627 & 0.138 & 0.602 \\
\hline $\mathrm{Fe} 3+$ & 0.002 & 0.007 & 0.009 & 0.000 & 0.010 & 0.003 & 0.000 & 0.000 \\
\hline $\mathrm{Si}$ & 0.995 & 0.996 & 0.994 & 0.999 & 0.993 & 0.997 & 0.997 & 0.999 \\
\hline $\mathrm{Al}$ & 0.007 & 0.002 & 0.003 & 0.007 & 0.007 & 0.003 & 0.004 & 0.002 \\
\hline $\mathrm{Ca}$ & 0.015 & 0.005 & 0.004 & 0.010 & 0.017 & 0.001 & 0.011 & 0.002 \\
\hline $\mathrm{Mg}$ & 1.973 & 1.404 & 1.770 & 1.379 & 1.968 & 1.358 & 1.845 & 1.383 \\
\hline $\mathrm{Cr}$ & 0.002 & 0.001 & 0.003 & 0.003 & 0.001 & 0.001 & 0.004 & 0.001 \\
\hline Mn & 0.000 & 0.004 & 0.002 & 0.006 & 0.000 & 0.005 & 0.001 & 0.005 \\
\hline $\mathrm{Ni}$ & 0.000 & 0.006 & 0.001 & 0.005 & 0.000 & 0.005 & 0.000 & 0.006 \\
\hline$\sum$ cations & 3.001 & 3.002 & 3.003 & 2.996 & 3.003 & 3.001 & 2.999 & 3.000 \\
\hline \multicolumn{9}{|c|}{$\mathrm{Fe} /(\mathrm{Fe}+\mathrm{Mg})$ ratio (in\%) } \\
\hline & 0.45 & 29.37 & 11.27 & 29.86 & 0.79 & 31.71 & 6.96 & 30.33 \\
\hline
\end{tabular}


Table 3 (continue):

\begin{tabular}{|c|c|c|c|c|c|c|c|c|c|c|c|c|c|c|c|c|c|c|c|c|}
\hline \multirow{3}{*}{$\begin{array}{l}\text { Profile \# } \\
\text { NWA } 4423\end{array}$} & \multicolumn{2}{|c|}{$\# 1$} & \multicolumn{2}{|c|}{$\# 2$} & \multicolumn{2}{|c|}{$\# 3$} & \multicolumn{2}{|c|}{$\# 4$} & \multicolumn{2}{|c|}{$\# 5$} & \multicolumn{2}{|c|}{$\# 6$} & \multicolumn{2}{|c|}{$\# 7$} & \multicolumn{2}{|c|}{ \#8 } & \multicolumn{2}{|c|}{49} & \multicolumn{2}{|c|}{$\# 10$} \\
\hline & \multicolumn{2}{|c|}{ Isolated olivine } & \multicolumn{2}{|c|}{ Anhedral olivine } & \multicolumn{2}{|c|}{ Anhedral olivine } & \multicolumn{2}{|c|}{ Euhedral olivine } & \multicolumn{2}{|c|}{ Isolated olivine } & \multicolumn{2}{|c|}{ Euhedral olivine } & \multicolumn{2}{|c|}{ Isolated olivine } & \multicolumn{2}{|c|}{ Anhedral olivine } & \multicolumn{2}{|c|}{ Anhedral olivine } & \multicolumn{2}{|c|}{ Anhedral olivine } \\
\hline & Core & Border & Core & Border & Core & Border & Core & Border & Core & Border & Core & Border & Core & Border & Core & Border & Core & Border & Core & Border \\
\hline $\mathrm{FeO}$ & 0.28 & 26.41 & 0.29 & 26.73 & 9.96 & 23.93 & 11.59 & 25.67 & 0.56 & 27.34 & 3.34 & 28.45 & 8.95 & 26.09 & 4.14 & 26.79 & 0.84 & 26.81 & 3.79 & 25.12 \\
\hline $\mathrm{Fe} 2 \mathrm{O} 3$ & 0.36 & 0.66 & 0.83 & 0.00 & 1.27 & 0.70 & 0.49 & 0.02 & 0.00 & 0.22 & 0.43 & 0.98 & 0.06 & 0.67 & 0.00 & 0.62 & 0.00 & 0.51 & 0.00 & 0.00 \\
\hline $\mathrm{SiO} 2$ & 42.46 & 37.34 & 42.33 & 37.61 & 40.44 & 37.73 & 40.36 & 36.30 & 42.60 & 37.39 & 42.29 & 36.73 & 40.94 & 37.46 & 42.01 & 37.33 & 42.64 & 37.03 & 41.64 & 37.34 \\
\hline $\mathrm{Al} 2 \mathrm{O} 3$ & 0.23 & 0.23 & 0.26 & 0.13 & 0.02 & 0.01 & 0.01 & 1.19 & 0.29 & 0.12 & 0.01 & 0.34 & 0.09 & 0.01 & 0.06 & 0.04 & 0.14 & 0.30 & 0.27 & 1.19 \\
\hline $\mathrm{CaO}$ & 0.52 & 0.09 & 0.60 & 0.24 & 0.13 & 0.08 & 0.08 & 0.06 & 0.65 & 0.03 & 0.01 & 0.18 & 0.30 & 0.09 & 0.35 & 0.09 & 0.52 & 0.05 & 0.21 & 0.19 \\
\hline $\mathrm{MgO}$ & 56.58 & 35.06 & 56.35 & 35.12 & 48.62 & 36.98 & 47.51 & 34.90 & 56.37 & 34.62 & 54.87 & 33.19 & 49.72 & 35.35 & 53.69 & 34.79 & 56.30 & 34.59 & 53.73 & 35.47 \\
\hline $\mathrm{Cr} 2 \mathrm{O} 3$ & 0.07 & 0.02 & 0.08 & 0.09 & 0.01 & n.d. & 0.04 & 1.45 & 0.07 & 0.06 & 0.01 & 0.42 & 0.16 & 0.05 & 0.11 & 0.05 & 0.12 & 0.39 & 0.31 & 0.22 \\
\hline $\mathrm{MnO}$ & n.d. & 0.25 & 0.03 & 0.20 & 0.08 & 0.20 & 0.09 & 0.14 & 0.02 & 0.24 & 0.06 & 0.26 & 0.04 & 0.23 & 0.03 & 0.23 & n.d. & 0.20 & 0.05 & 0.18 \\
\hline $\mathrm{NiO}$ & n.d. & 0.29 & 0.02 & 0.24 & 0.02 & 0.18 & 0.13 & 0.25 & 0.01 & 0.26 & n.d. & 0.29 & 0.07 & 0.26 & n.d. & 0.25 & n.d. & 0.29 & 0.01 & 0.21 \\
\hline Total & 100.50 & 100.37 & 100.78 & 100.35 & 100.55 & 99.82 & 100.32 & 99.96 & 100.57 & 100.27 & 101.00 & 100.83 & 100.34 & 100.20 & 100.39 & 100.20 & 100.56 & 100.17 & 100.01 & 99.92 \\
\hline \multicolumn{21}{|c|}{ Cation number in the basis of 4 oxygens } \\
\hline $\mathrm{Fe} 2+$ & 0.005 & 0.587 & 0.006 & 0.593 & 0.204 & 0.528 & 0.239 & 0.571 & 0.011 & 0.609 & 0.066 & 0.638 & 0.182 & 0.580 & 0.082 & 0.597 & 0.016 & 0.599 & 0.076 & 0.555 \\
\hline $\mathrm{Fe} 3+$ & 0.006 & 0.013 & 0.015 & 0.000 & 0.024 & 0.014 & 0.009 & 0.000 & 0.000 & 0.004 & 0.008 & 0.020 & 0.001 & 0.013 & 0.000 & 0.012 & 0.000 & 0.010 & 0.000 & 0.000 \\
\hline $\mathrm{Si}$ & 0.994 & 0.992 & 0.992 & 0.997 & 0.993 & 0.996 & 0.997 & 0.966 & 0.997 & 0.996 & 0.998 & 0.985 & 0.997 & 0.996 & 0.999 & 0.995 & 0.998 & 0.988 & 0.993 & 0.986 \\
\hline $\mathrm{Al}$ & 0.006 & 0.007 & 0.007 & 0.004 & 0.001 & 0.000 & 0.000 & 0.037 & 0.008 & 0.004 & 0.000 & 0.011 & 0.003 & 0.000 & 0.002 & 0.001 & 0.004 & 0.009 & 0.008 & 0.037 \\
\hline $\mathrm{Ca}$ & 0.013 & 0.003 & 0.015 & 0.007 & 0.003 & 0.002 & 0.002 & 0.002 & 0.016 & 0.001 & 0.000 & 0.005 & 0.008 & 0.002 & 0.009 & 0.003 & 0.013 & 0.001 & 0.005 & 0.005 \\
\hline $\mathrm{Mg}$ & 1.975 & 1.389 & 1.968 & 1.388 & 1.779 & 1.455 & 1.749 & 1.385 & 1.965 & 1.375 & 1.929 & 1.326 & 1.804 & 1.400 & 1.904 & 1.383 & 1.965 & 1.376 & 1.911 & 1.397 \\
\hline $\mathrm{Cr}$ & 0.001 & 0.001 & 0.001 & 0.002 & 0.000 & 0.000 & 0.001 & 0.030 & 0.001 & 0.001 & 0.000 & 0.009 & 0.003 & 0.001 & 0.002 & 0.001 & 0.002 & 0.008 & 0.006 & 0.005 \\
\hline $\mathrm{Mn}$ & 0.000 & 0.006 & 0.001 & 0.004 & 0.002 & 0.004 & 0.002 & 0.003 & 0.000 & 0.005 & 0.001 & 0.006 & 0.001 & 0.005 & 0.001 & 0.005 & 0.000 & 0.005 & 0.001 & 0.004 \\
\hline $\mathrm{Ni}$ & 0.000 & 0.006 & & & 0.000 & 0.004 & 0.003 & 0.005 & 0.000 & 0.006 & 0.000 & 0.006 & 0.001 & 0.006 & 0.000 & 0.005 & 0.000 & 0.006 & 0.000 & 0.005 \\
\hline$\Sigma$ cations & 3.002 & 3.004 & 3.004 & 3.000 & 3.007 & 3.004 & 3.003 & 3.000 & 2.999 & 3.001 & 3.002 & 3.006 & 3.000 & 3.004 & 2.999 & 3.003 & 2.999 & 3.003 & 3.000 & 2.993 \\
\hline \multicolumn{21}{|c|}{$\mathrm{Fe} /(\mathrm{Fe}+\mathrm{Mg})$ ratio (in\%) } \\
\hline & 0.59 & 30.17 & 1.02 & 29.93 & 11.36 & 27.15 & 12.44 & 29.22 & 0.55 & 30.86 & 3.67 & 33.14 & 9.23 & 29.76 & 4.15 & 30.61 & 0.83 & 30.67 & 3.81 & 28.43 \\
\hline
\end{tabular}


Table 3 (continue):

\begin{tabular}{|c|c|c|c|c|c|c|c|c|}
\hline Profile \# & & 1 & & 2 & & & $\#$ & 4 \\
\hline \multirow{2}{*}{ Tnz 057} & \multicolumn{2}{|c|}{ Anhedral olivine } & \multicolumn{2}{|c|}{ Anhedral olivine } & \multicolumn{2}{|c|}{ Anhedral olivine } & \multicolumn{2}{|c|}{ Anhedral olivine } \\
\hline & Core & Border & Core & Border & Core & Border & Core & Border \\
\hline$\overline{\mathrm{FeO}}$ & 1.06 & 26.17 & 1.64 & 27.19 & 1.02 & 24.95 & 1.27 & 18.60 \\
\hline $\mathrm{Fe} 2 \mathrm{O} 3$ & 0.05 & 0.00 & 0.16 & 0.00 & 0.36 & 0.00 & 0.00 & 0.00 \\
\hline $\mathrm{SiO} 2$ & 42.39 & 37.48 & 42.11 & 37.45 & 42.14 & 37.95 & 42.58 & 39.18 \\
\hline $\mathrm{Al} 2 \mathrm{O} 3$ & 0.25 & 0.10 & 0.13 & 0.03 & 0.25 & 0.13 & 0.25 & 0.14 \\
\hline $\mathrm{CaO}$ & 0.34 & 0.05 & 0.22 & 0.05 & 0.54 & 0.06 & 0.58 & 0.37 \\
\hline $\mathrm{MgO}$ & 56.18 & 35.16 & 55.52 & 34.60 & 55.72 & 36.64 & 55.77 & 41.55 \\
\hline $\mathrm{Cr} 2 \mathrm{O} 3$ & 0.11 & 0.02 & 0.11 & 0.01 & 0.10 & 0.05 & 0.08 & 0.09 \\
\hline $\mathrm{MnO}$ & n.d. & 0.19 & n.d. & 0.22 & n.d. & 0.23 & n.d. & 0.11 \\
\hline $\mathrm{NiO}$ & n.d. & 0.31 & 0.01 & 0.29 & n.d. & 0.25 & n.d. & 0.32 \\
\hline Total & 100.37 & 99.47 & 99.91 & 99.84 & 100.12 & 100.26 & 100.53 & 100.36 \\
\hline \multicolumn{9}{|c|}{ Cation number in the basis of 4 oxygens } \\
\hline $\mathrm{Fe} 2+$ & 0.021 & 0.584 & 0.032 & 0.607 & 0.020 & 0.549 & 0.025 & 0.396 \\
\hline $\mathrm{Fe} 3+$ & 0.001 & 0.000 & 0.003 & 0.000 & 0.006 & 0.000 & 0.000 & 0.000 \\
\hline $\mathrm{Si}$ & 0.995 & 1.000 & 0.996 & 1.000 & 0.994 & 0.998 & 0.999 & 0.999 \\
\hline $\mathrm{Al}$ & 0.007 & 0.003 & 0.004 & 0.001 & 0.007 & 0.004 & 0.007 & 0.004 \\
\hline $\mathrm{Ca}$ & 0.008 & 0.001 & 0.006 & 0.002 & 0.014 & 0.002 & 0.014 & 0.010 \\
\hline $\mathrm{Mg}$ & 1.966 & 1.398 & 1.958 & 1.378 & 1.959 & 1.436 & 1.950 & 1.578 \\
\hline $\mathrm{Cr}$ & 0.002 & 0.000 & 0.002 & 0.000 & 0.002 & 0.001 & 0.001 & 0.002 \\
\hline Mn & 0.000 & 0.004 & 0.000 & 0.005 & 0.000 & 0.005 & 0.000 & 0.002 \\
\hline $\mathrm{Ni}$ & 0.000 & 0.007 & 0.000 & 0.006 & 0.000 & 0.005 & 0.000 & 0.007 \\
\hline$\sum$ cations & 3.000 & 2.998 & 3.001 & 2.999 & 3.002 & 3.000 & 2.997 & 2.998 \\
\hline \multicolumn{9}{|c|}{$\mathrm{Fe} /(\mathrm{Fe}+\mathrm{Mg})$ ratio (in\%) } \\
\hline & 1.10 & 29.46 & 1.77 & 30.60 & 1.33 & 27.64 & 1.26 & 20.07 \\
\hline
\end{tabular}


Table 4: Values of the diffusion lengths of the first $\left(a_{1}\right)$ and second $\left(a_{2}\right)$ stage of our diffusion modeling for the steepest chemical profile measured by EPMA for each sample. We also reported the values, for Fe, of $C_{\mathrm{S}}, C_{0}$, and $C_{1}$, as well as angles between the [100], [010], and [001] directions and the chemical profiles. Values of $\% \mathrm{Fa}$ are given considering a pure $\mathrm{Mg}_{2} \mathrm{SiO}_{4}-\mathrm{Fe}_{2} \mathrm{SiO}_{4}$ solid solution.

\begin{tabular}{|c|c|c|c|c|c|c|c|c|c|c|c|c|}
\hline Profile & Profile \# & $\begin{array}{l}a_{1} \\
(\mathrm{mic} \\
\end{array}$ & $\begin{array}{c}a_{2} \\
\text { ons) }\end{array}$ & $\begin{array}{r}C \\
(\mathrm{at} \%) \\
\end{array}$ & $\begin{array}{l}\mathrm{C}_{\mathrm{s}} \\
(\% \mathrm{Fa})\end{array}$ & $\begin{array}{r}C \\
(\mathrm{at} \%) \\
\end{array}$ & $(\% \mathrm{Fa})$ & $\begin{array}{r}C \\
(\text { at } \%) \\
\end{array}$ & $(\% \mathrm{Fa})$ & $\begin{array}{c}\text { Angle between } \\
{[100] \text { and }} \\
\text { diffusion profile }\end{array}$ & $\begin{array}{c}\text { Angle between } \\
{[010] \text { and }} \\
\text { diffusion profile }\end{array}$ & $\begin{array}{c}\text { Angle between } \\
\text { [001] and } \\
\text { diffusion profile }\end{array}$ \\
\hline $\mathrm{DaG} 431$ & 5 & 15 & 6 & 22 & 77.0 & 0.15 & 0.5 & 9.57 & 33.5 & $54^{\circ}$ & $60^{\circ}$ & $38^{\circ}$ \\
\hline NWA 4724 & 3 & 26 & 7 & 24 & 84.0 & 0.16 & 0.5 & 9.04 & 31.7 & $73^{\circ}$ & $35^{\circ}$ & $50^{\circ}$ \\
\hline NWA 4423 & 2 & 46 & 11 & 25 & 87.5 & 0.29 & 1.0 & 8.49 & 29.8 & $45^{\circ}$ & $28^{\circ}$ & $78^{\circ}$ \\
\hline Tnz 057 & 1 & 63 & 23 & 20 & 70.0 & 0.31 & 1.0 & 8.82 & 30.9 & $56^{\circ}$ & $32^{\circ}$ & $25^{\circ}$ \\
\hline
\end{tabular}




\section{Figures}
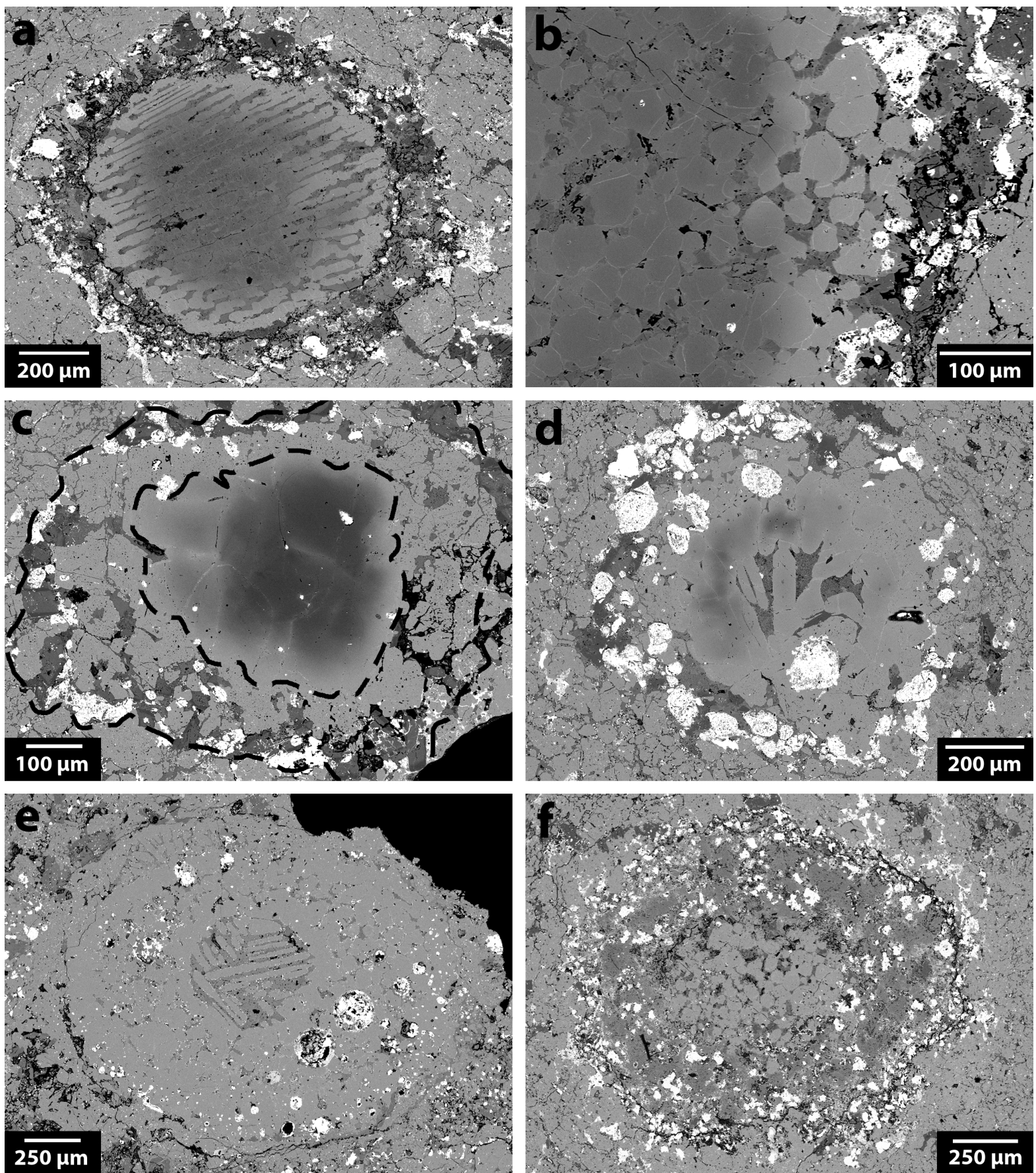

Fig. 1. BSE images of chondrules in Tnz 057 (a, f), NWA 4423 (b, c, and d), and NWA 4422 (e). From (a) to (d), olivine in chondrules becomes more chemically re-equilibrated with the matrix olivines. An interstitial mixture of plagioclase and pyroxene and containing numerous voids is present in the chondrule ( $a, b$, and). The chemically zoned olivine in the core of the chondrule (c) is surrounded by olivine grains (delimited by the dashed lines) containing numerous micron-sized vesicles and inclusions of magnetite and sulfides (mainly pentlandite). Olivine in chondrules (e) and (f) are chemically re-equilibrated with the host matrix. Excepted in (e), chondrules are surrounded by igneous rims mainly composed, in variable proportions, of pyroxene, plagioclase, magnetite, and sulfides. 

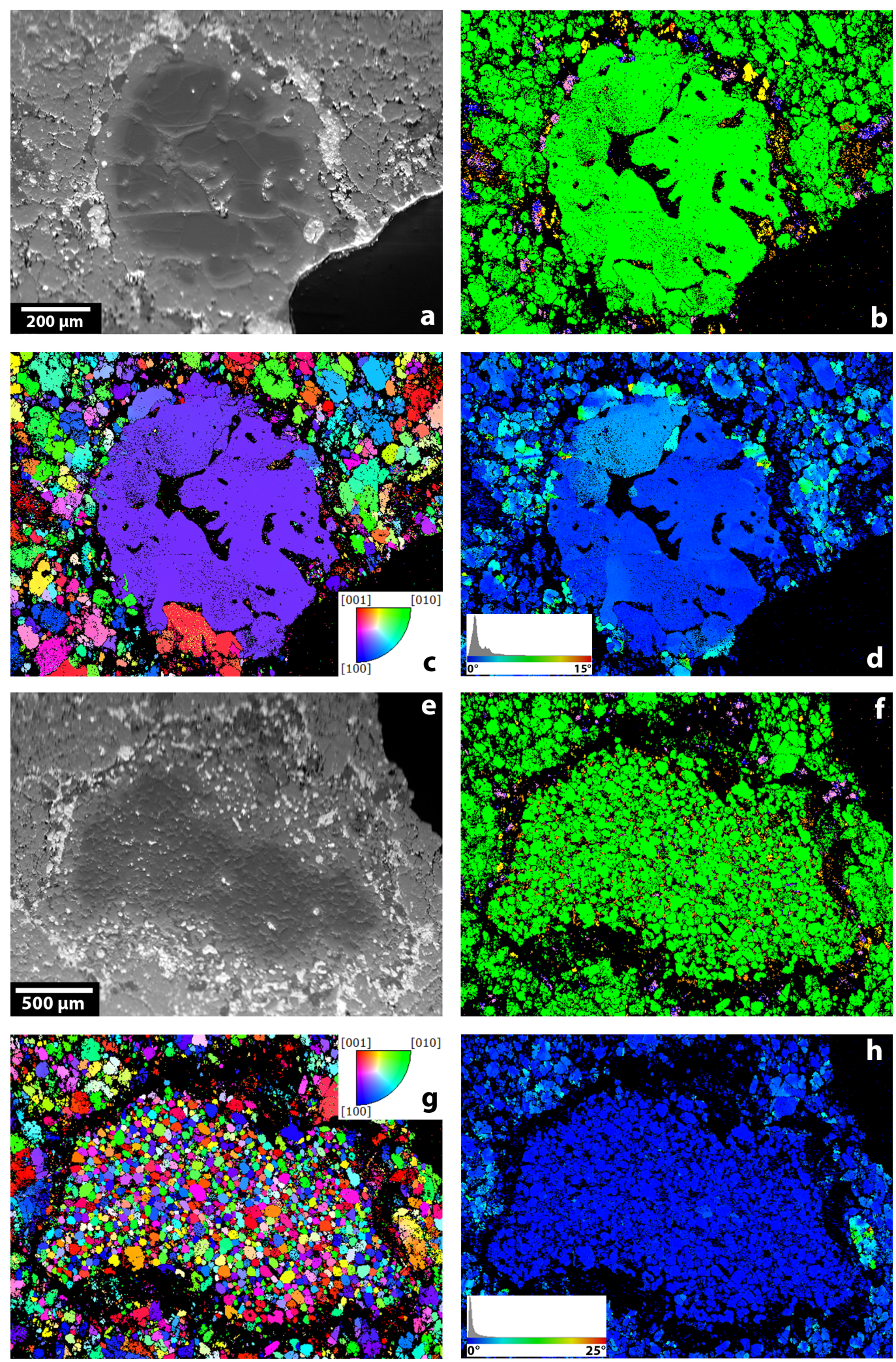

Fig. 2. Chondrules in NWA 4423 composed of large anhedral (a-d) and euhedral (e-h) olivine grains. (a, e) BSE images. (b f) Color-coded phase maps obtained using the indexing of EBSD patterns. Olivine appears in green, magnetite in yellow, and plagioclase in purple. Black areas correspond to a lack of indexed EBSD patterns (e.g., only a few Kikuchi bands) or to recrystallized mesostasis. (c, g) Color-coded EBSD orientation map (IPF-X) showing the crystallographic orientation of olivine relative de the $\mathrm{X}$-axis of the sample (= horizontal axis of the image). (d,h) Color-coded misorientation maps showing the variation of crystallographic orientation of olivine grains. For each EBSD pattern, a color-coded value is assigned as a function of the difference between the crystallographic orientation obtained from the pattern considered and the mean orientation of the grain in which this pattern was obtained. 

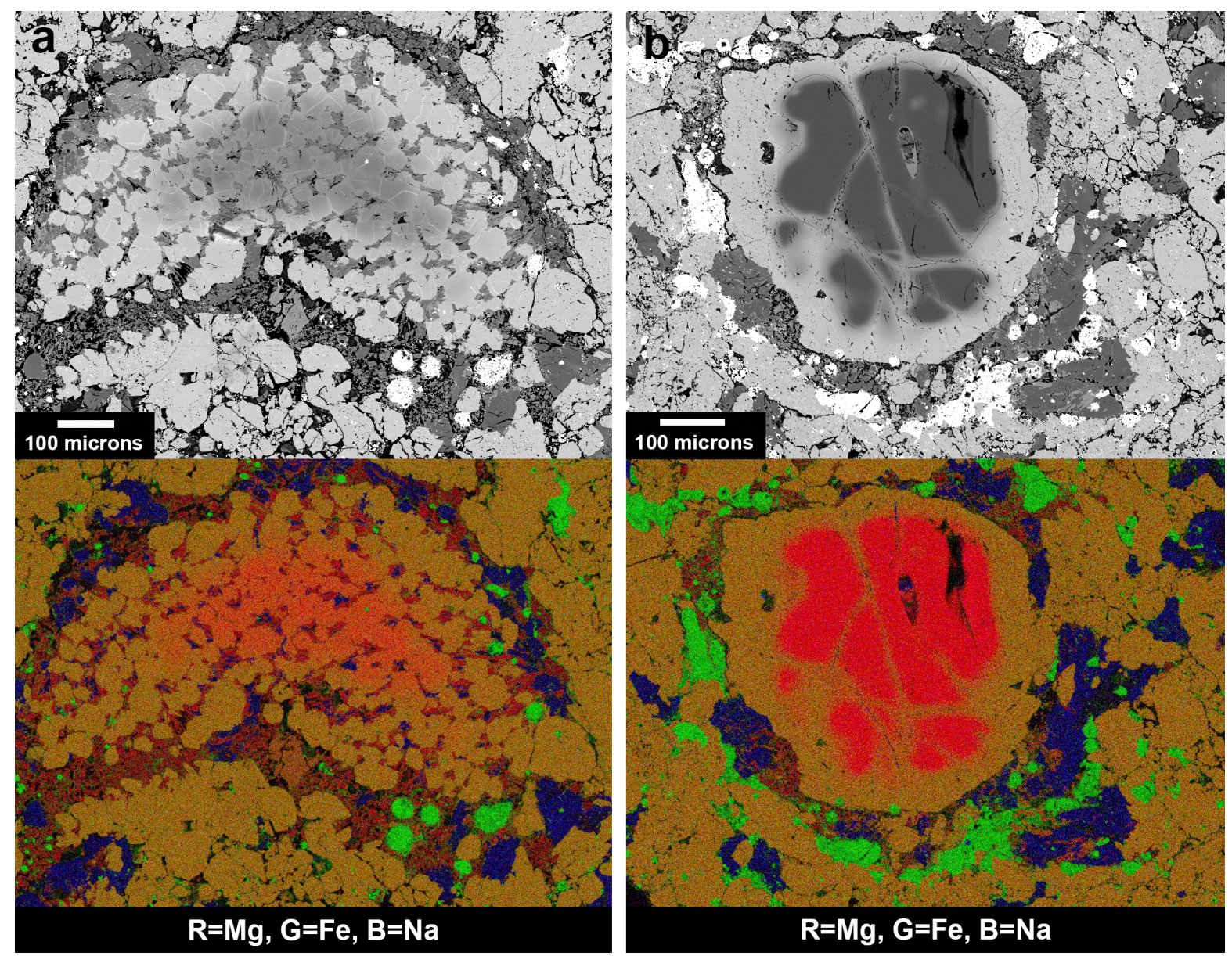

Fig. 3. BSE images and EDS compositional maps in RGB colors $(\mathrm{R}=\mathrm{Mg}, \mathrm{G}=\mathrm{Fe}, \mathrm{B}=\mathrm{Na})$ of two unequilibrated chondrules from NWA 4724 embedded in a recrystallized matrix. In EDS maps, Fe-rich olivine appears in orange, Mg-rich olivine in pink, plagioclase in blue, magnetite in green, and pyroxene in red. (a) Chondrule composed of numerous euhedral olivine grains and showing a diffusive front parallel to the matrix-chondrule boundaries. (b) Chondrule composed of a large olivine grain showing intracrystalline diffusion, as well as diffusion at grain boundaries and along fractures. The fine-grained interstitial mixture of plagioclase and pyroxene in (a) and the ovoid "inclusion" (pyroxene+plagioclase) in the center of the chondrule (b) correspond to recrystallized mesostases. 

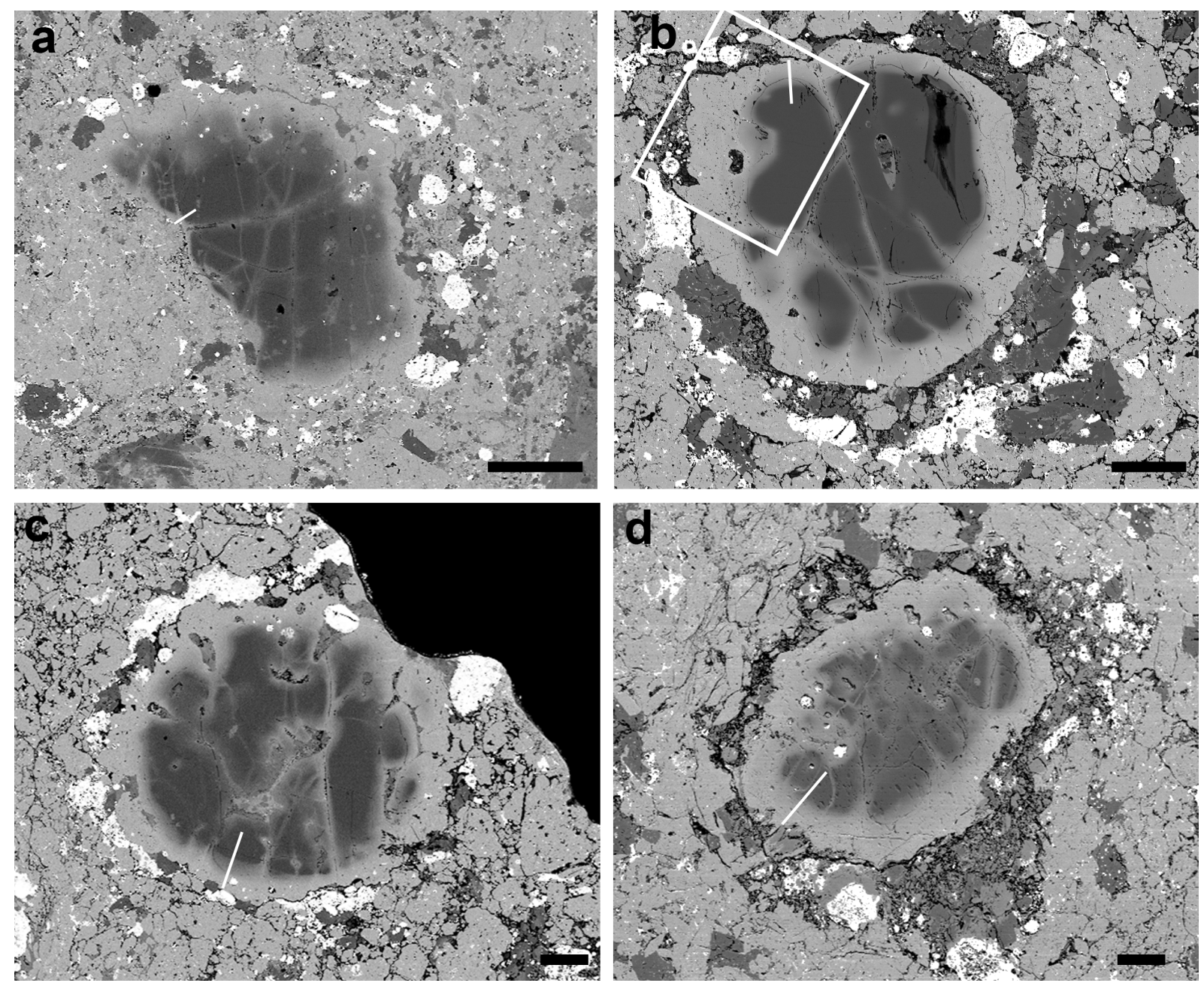

Fig. 4. BSE images, in DaG 431 (a), NWA 4724 (b), NWA 4423 (c), and Tnz 057 (d), of unequilibrated chondrules or

chondrule fragment in which we measured some chemical profiles (white lines) for quantitative study. These chondrules are composed of anhedral olivine grains. The chemical profiles reported here are those showing the smallest diffusion lengths among all profiles measured for each sample. Scale bars are 100 microns. The white box in (b) indicates the area that is shown in more detail in Fig 5. 


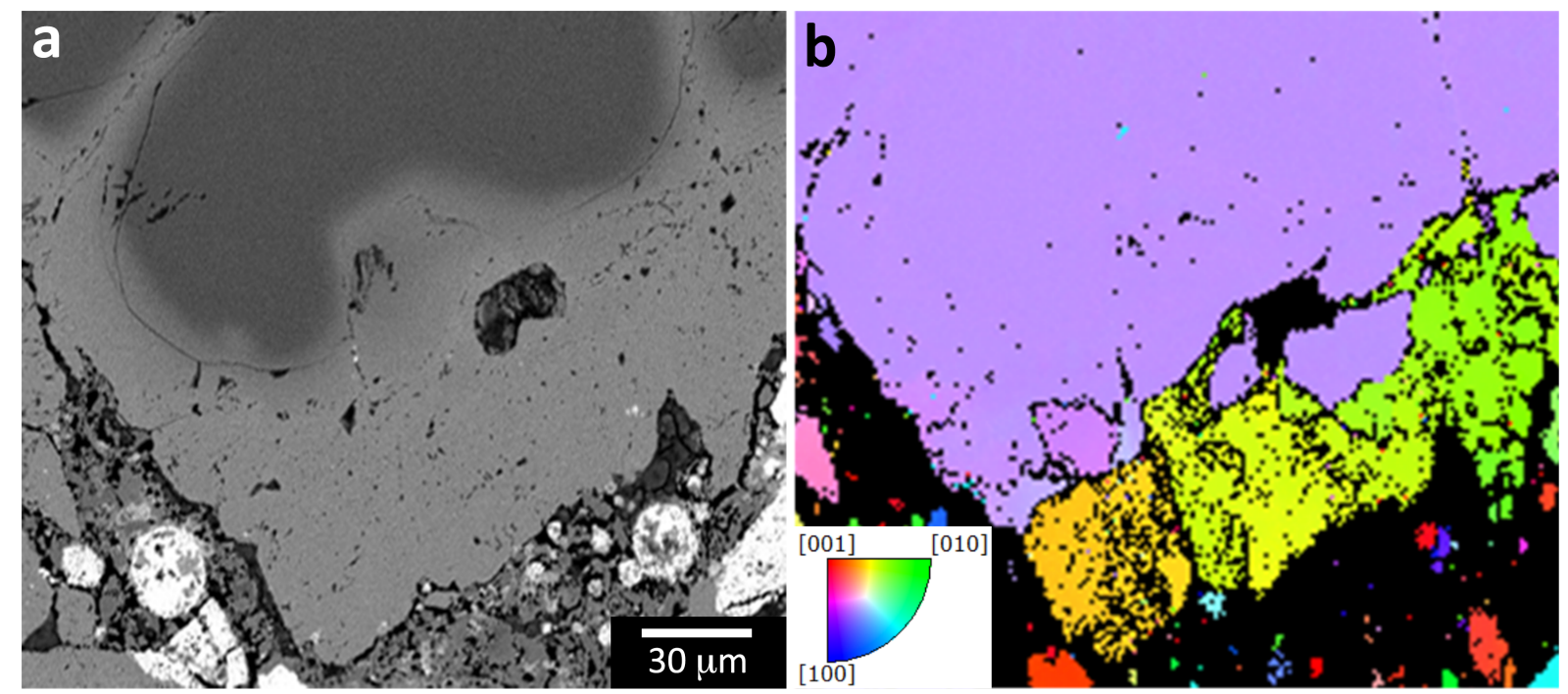

Fig. 5. BSE image (a) and color-coded EBSD orientation map (IPF-Y) (b) of the boxed area in Fig. 4b showing Fe-rich

olivine grains containing numerous micron-sized vesicles and a few tiny inclusions of opaque phases. The vesiculated olivine is chemically equilibrated with the host matrix and displays different crystallographic orientations relative to the chemically zoned and non vesiculated olivine. 

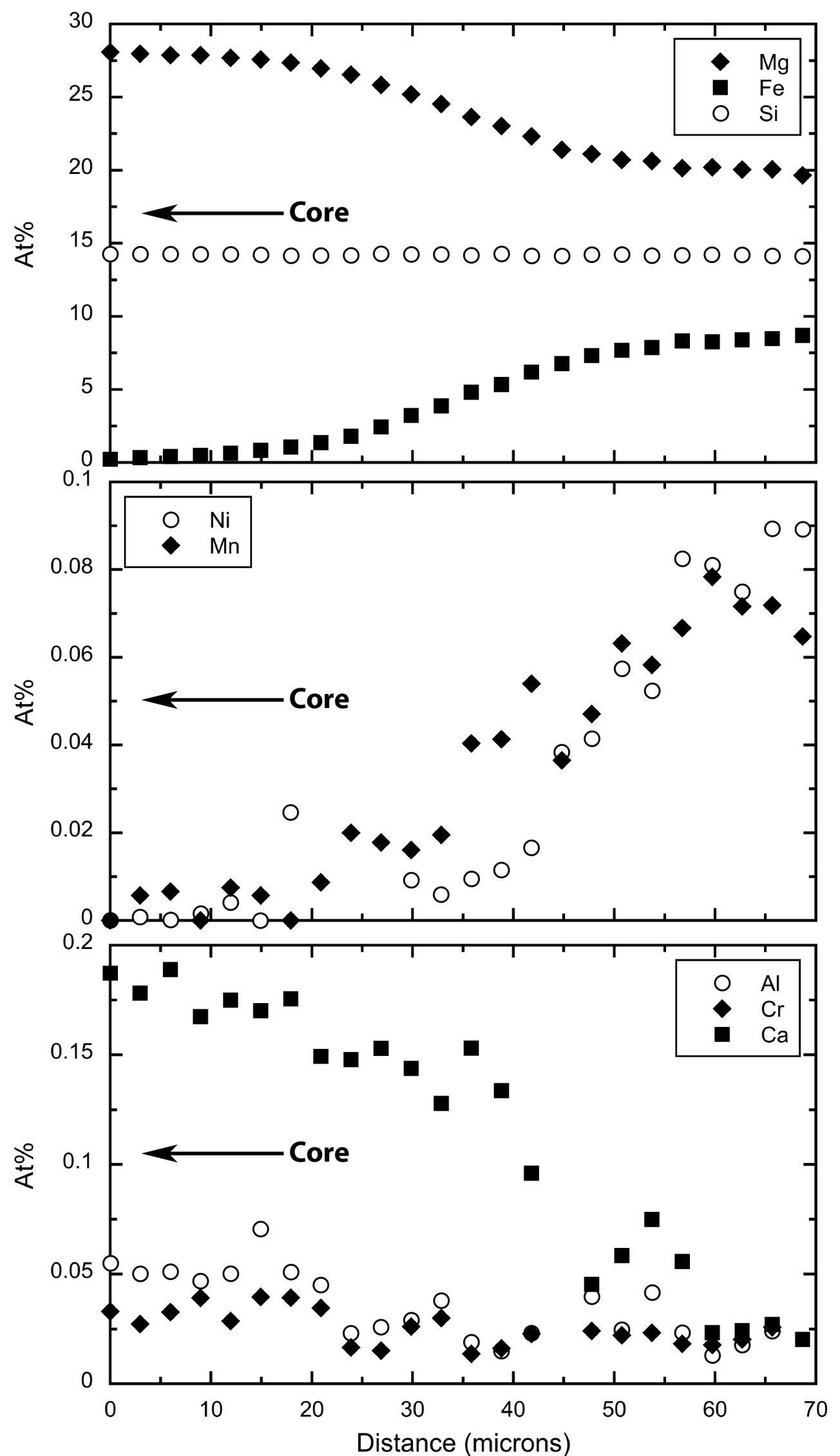

Fig. 6. Concentration profiles of $\mathrm{Fe}, \mathrm{Mg}, \mathrm{Si}, \mathrm{Ni}, \mathrm{Mn}, \mathrm{Al}, \mathrm{Ca}$, and $\mathrm{Cr}$ in an anhedral olivine crystal from an unequilibrated chondrule in NWA 4423. 


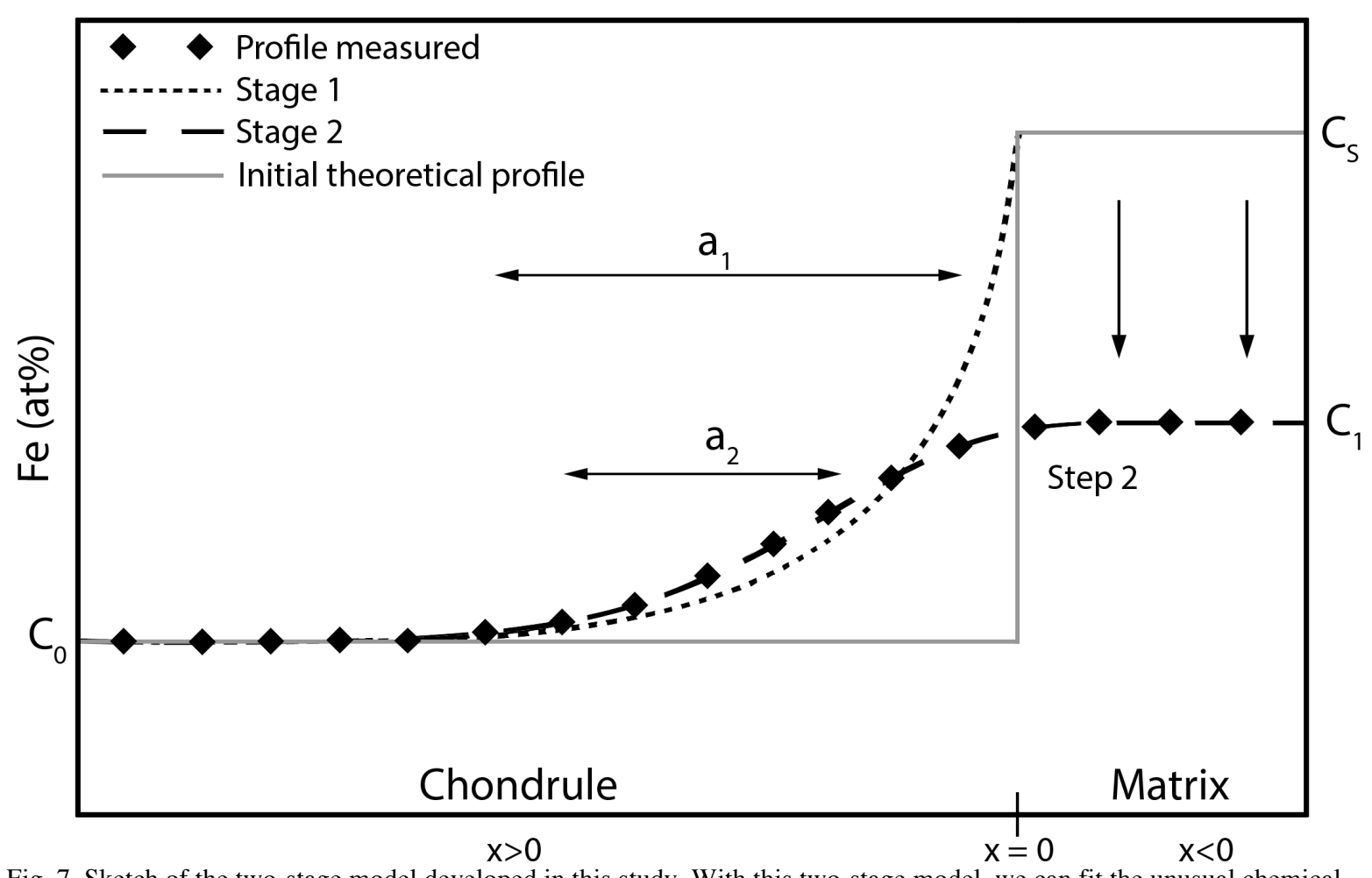

Fig. 7. Sketch of the two-stage model developed in this study. With this two-stage model, we can fit the unusual chemical profiles measured in olivines from unequilibrated chondrules and explain why the inflexion points are not situated at the chondrule/matrix interfaces $(x=0)$. At the beginning of the modeling, $C_{0}, C_{1}$, and $x$ are known. During the first stage, the composition for $x<0$ (matrix) remains constant. The best fit, using the Eq. (2), of at least $75 \%$ of the data situated below the inflexion point of the chemical profile measured gives a presumed initial concentration of the matrix $\left(C_{\mathrm{S}}\right)$. The duration of this first stage is calculated from the diffusion length of this first fit $\left(a_{1}\right)$. Then, and due to the diffusion of Fe within the chondrule, the concentration in matrix olivine decreases to the value measured by EPMA $\left(C_{1}\right)$. The second stage of this model consists of the diffusion of Fe from the matrix with a composition $C_{1}$, to the chondrule already partially equilibrated. To estimate the duration of this second stage, we fit the chemical profile measured using the Eq. (3) and thus obtain a second diffusion length $\left(a_{2}\right)$. The sum of the durations inferred from the two diffusion lengths corresponding to the two stages thus gives a good approximation of the total duration of the diffusion process. 

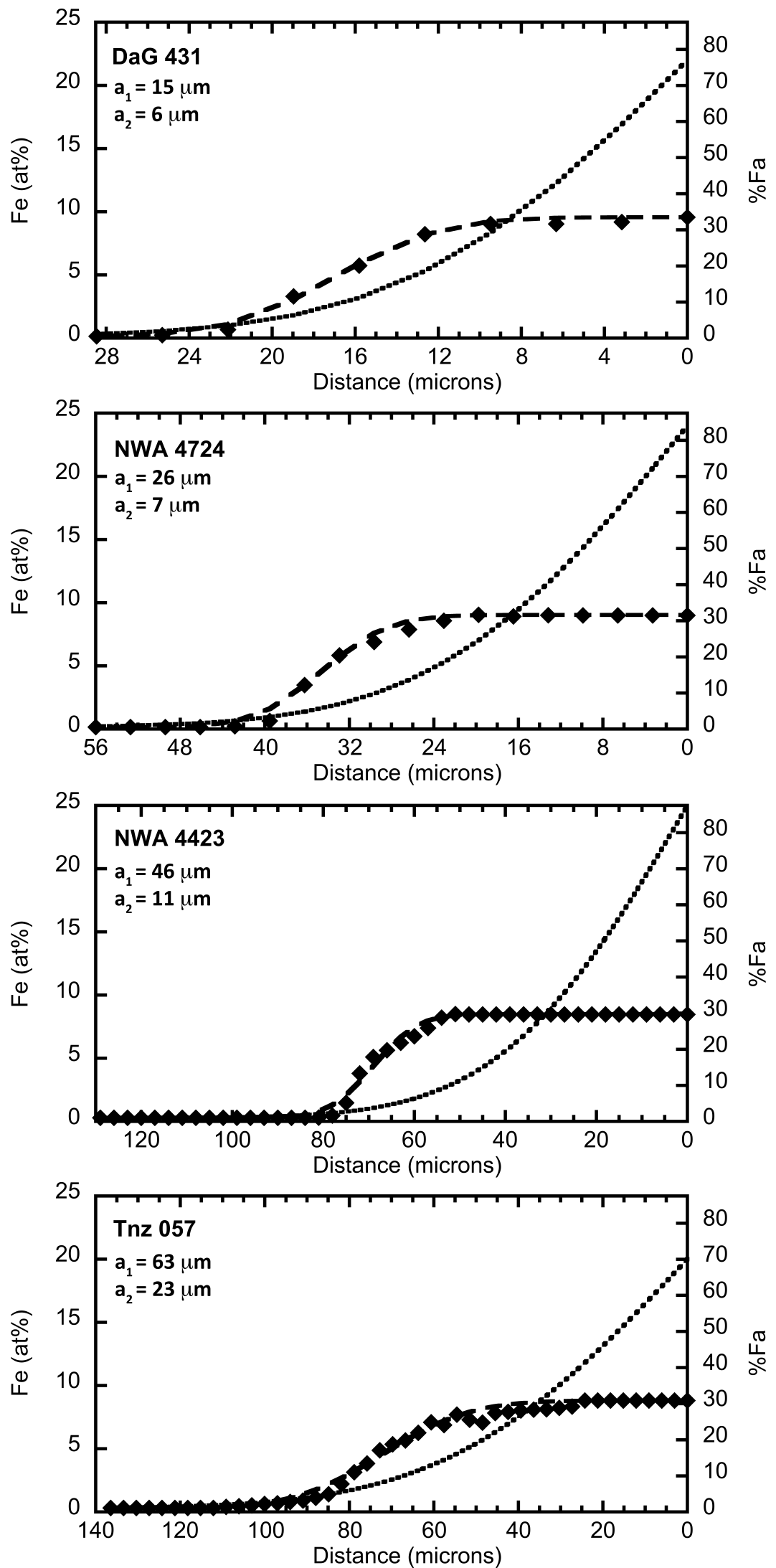

Fig. 8. Steepest EPMA chemical profiles (for Fe; filled diamonds) measured in zoned olivines in chondrules from DaG 431 (profile \#5), NWA 4724 (profile \#3), NWA 4423 (profile \#2), and Tnz 057 (profile \#1), fit by a two-stage diffusion process, using Eq. (2) (dotted line) then Eq. (3) (dashed line). These profiles refer to the specific profile numbers in Tables 3 and 4. Matrix/chondrule interfaces correspond to the right limit of these plots $(\mathrm{x}=0)$. 


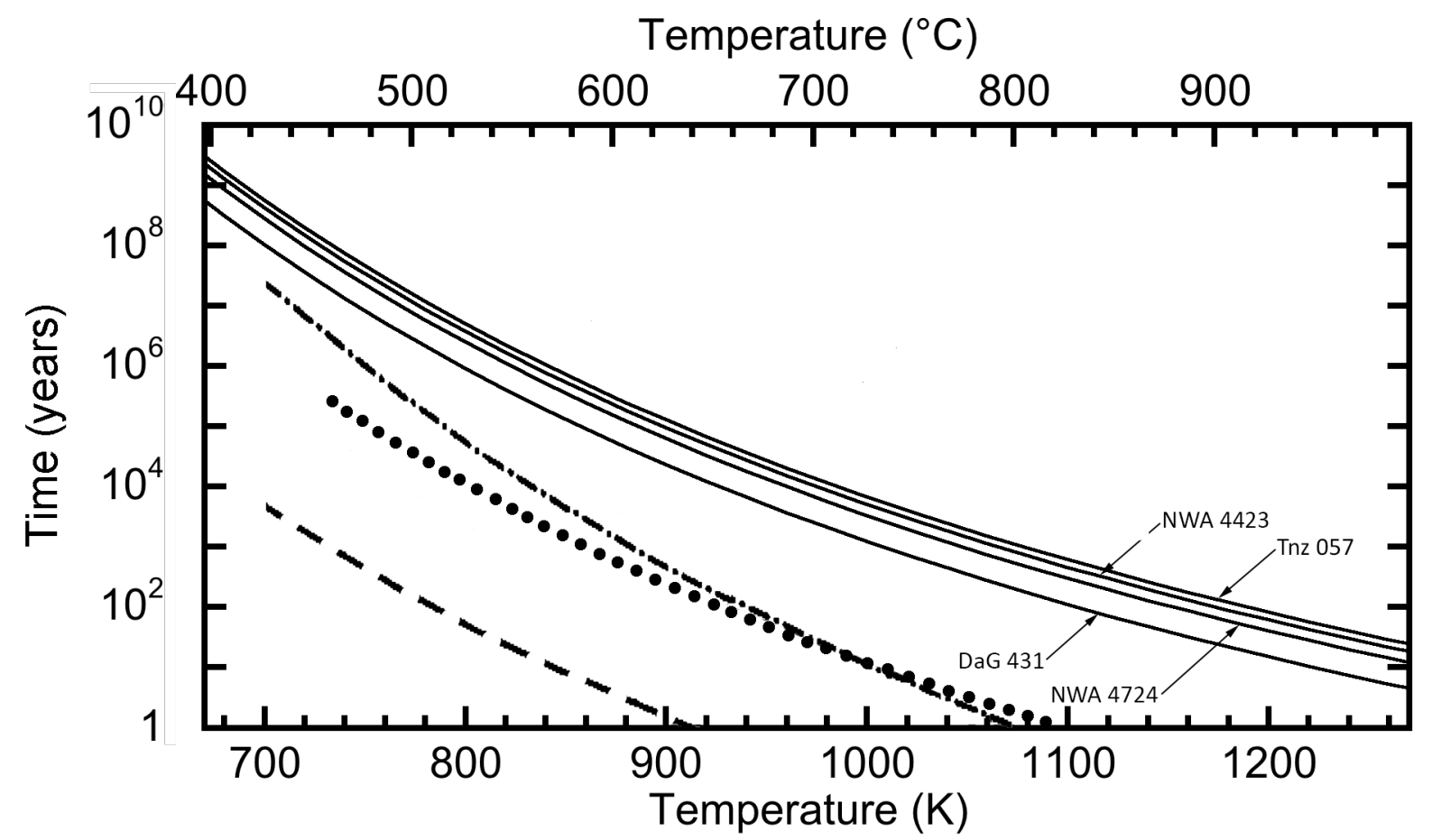

Fig. 9. Time-temperature curves obtained for the steepest chemical profiles measured in DaG 431, NWA 4724, NWA 4423, and Tnz 057. We also reported for comparison data of $\mathrm{Fe} / \mathrm{Mg}$ interdiffusion realized in previous studies for zoned olivines found in the matrix (Cuvillier et al., 2013; dotted curve) and chondrules of Allende (Weinbruch et al., 1994; dashed curve, diffusion coefficient of Buening and Buseck (1973); dotted-dashed curve, diffusion coefficient of Nakamura and Schmalzried (1984)). 